The FASEB Journal express article 10.1096/fj.05-4305fje. Published online February 2, 2006.

\title{
Role of endoplasmic reticulum depletion and multidomain proapoptotic BAX and BAK proteins in shaping cell death after hypericin-mediated photodynamic therapy
}

Esther Buytaert,* Geert Callewaert,* Nico Hendrickx,* Luca Scorrano, ${ }^{\dagger}$ Dieter Hartmann,* Ludwig Missiaen,* Jackie R. Vandenheede, ${ }^{*}$ Ingeborg Heirman, ${ }^{\ddagger}$ Johan Grooten, ${ }^{\ddagger}$ and Patrizia Agostinis*

*Dept. Molecular \& Cell Biology, Faculty of Medicine, Catholic University of Leuven, Belgium; ${ }^{\dagger}$ Dulbecco-Telethon Institute, Venetian Institute of Molecular Medicine, Padova, Italy; ${ }^{\ddagger}$ Department for Molecular Biomedical Research, Unit of Molecular Immunology, Flanders Interuniversity Institute for Biotechnology and Ghent University, Belgium

*Corresponding author: Patrizia Agostinis, Division of Biochemistry, Campus Gasthuisberg, Herestraat 49, B-3000 Leuven, Belgium. E-mail: Patricia.Agostinis@med.kuleuven.ac.be

\section{ABSTRACT}

Both the commitment event and the modality of cell death in photodynamic therapy (PDT) remain poorly defined. We report that PDT with endoplasmic reticulum (ER)-associating hypericin leads to an immediate loss of SERCA2 protein levels, causing disruption of $\mathrm{Ca}^{2+}$ homeostasis and cell death. Protection of SERCA2 protein rescues ER-Ca ${ }^{2+}$ levels and prevents cell death, suggesting that SERCA2 photodestruction with consequent incapability of the ER to maintain intracellular $\mathrm{Ca}^{2+}$ homeostasis is causal to cell killing. Apoptosis is rapidly initiated after $\mathrm{ER}-\mathrm{Ca}^{2+}$ depletion and strictly requires the BAX/BAK gateway at the mitochondria. $\mathrm{Bax}^{-1-} \mathrm{Bak}^{-1-}$ double-knockout (DKO) cells are protected from apoptosis but undergo autophagyassociated cell death as revealed by electron microscopy and biochemical analysis. Autophagy inhibitors, but not caspase antagonists, significantly reduce death of DKO cells, suggesting that sustained autophagy is lethal. Thus, following ER photodamage and consequent disruption of $\mathrm{Ca}^{2+}$ homeostasis, BAX and BAK proteins model PDT-mediated cell killing, which is executed through apoptosis in their presence or via an autophagic pathway in their absence.

Key words: mitochondria • reactive oxygen species • cancer therapy

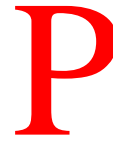

hotodynamic therapy (PDT) is an established and useful modality for the treatment of cancer. This therapy requires a photosensitizing agent (photosensitizer) selectively taken up by tumor cells, visible light, and molecular oxygen to generate reactive oxygen species (ROS), which ultimately cause tumor destruction (1). Hypericin, a powerful naturally occurring photosensitizer, is endowed with remarkable tumor localizing properties and in vivo antineoplastic activity upon irradiation, suggesting its clinical use as a promising PDT agent (2). Since apoptosis is a major in vivo response to hypericin-mediated PDT (3), modulation of the apoptotic vulnerability of the cancer cells is critical for the therapeutic efficacy of this drug. 
Multiple cell death modalities have been described at the morphological and biochemical levels and include apoptosis, necrosis, and cell death associated with the formation of autophagic vacuoles, which is a typical hallmark of autophagy (4-6). These forms of cell death are not mutually exclusive, and mounting evidence indicates that they may coexist in cells exposed to bona fide apoptotic stimuli or occur simultaneously under several physiological and pathological conditions (for a review, see refs 4-6).

Apoptosis, or type I cell death, is characterized by cell shrinkage, chromatin condensation and DNA fragmentation, membrane blebbing, activation of caspases, and phagocytosis by neighboring cells (7). It is well established that the activation of caspases in mammalian cells occurs mainly through death receptor activation (extrinsic pathway) or through mitochondrial outer membrane permeabilization (intrinsic pathway) (7). Intrinsic apoptosis can be initiated from signals originating from or converging on intracellular organelles, such as mitochondria, the endoplasmic reticulum (ER), or lysosomes, and is tightly controlled by the BCL-2 family members (7). Besides acting at the mitochondria where multidomain proapoptotic proteins BAX and BAK positively and antiapoptotic BCL-2 proteins negatively regulate cytochrome $c$ release, growing evidence indicates that these proteins crucially modulate $\left[\mathrm{Ca}^{2+}\right]_{\mathrm{ER}}$ as well (8-12).

Recent studies suggest that the ER acts as a critical control point in several apoptotic paradigms induced by cellular signals that cause a $\mathrm{Ca}^{2+}$ overload or perturbations in the $\mathrm{Ca}^{2+}$ homeostasis $(13,14)$. Evidence on a possible connection between intracellular $\mathrm{Ca}^{2+}$ and PDT-induced apoptosis is largely contradictory. Based on the use of the cell-permeable $\mathrm{Ca}^{2+}$ chelator BAPTAAM, either no role (15), a proapoptotic role (16), or even a protective (17) role for a PDTmediated $\left[\mathrm{Ca}^{2+}\right]_{\mathrm{cyt}}$ increase has been proposed. However, none of these studies directly measured steady-state $\mathrm{ER}^{-\mathrm{Ca}^{2+}}$ or agonist-releasable $\mathrm{Ca}^{2+}$ levels after PDT, and the issue of how perturbations in $\mathrm{Ca}^{2+}$ fluxes regulate cellular responses in PDT-treated cells remains largely unresolved.

Several biochemical studies have established that PDT with different sensitizers, including hypericin, mainly utilizes the mitochondrial pathway of caspase activation $(18,19)$. However, the inhibition of caspases or caspase-3 deficiency reportedly does not provide full protection either in vitro (18-20) or in vivo (21), arguing that PDT also engages caspase-independent pathways to kill cells.

The present study was undertaken to provide a better understanding of the commitment event and the modality of cell death after PDT with hypericin. Based on direct $\mathrm{Ca}^{2+}$ measurements with targeted aequorin constructs, we show that the commitment step in hypericin-based PDT-induced cell death is upstream of the BAX/BAK gateway, and it is caused by the loss of the native SERCA2 protein levels and consequent $\left[\mathrm{Ca}^{2+}\right]_{\text {ER }}$ depletion. Downstream of the ER, the multidomain BAX/BAK proteins are strictly required for fast effector caspase activation and induction of intrinsic apoptosis. However, in the absence of BAX and BAK, PDT kills the cells through a caspase-independent, autophagic cell death pathway. 


\section{MATERIALS AND METHODS}

\section{Materials}

Hypericin was prepared, purified, and dissolved in $\mathrm{Me}_{2} \mathrm{SO}$ as described in Chen et al (3). All cell culture products were obtained from Cambrex (Verviers, Belgium). Fetal calf serum was from Perbio Hyclone (Erembodegem, Belgium). Antibodies were purchased from Upstate (Waltham, MA) (BAX NT), BD PharMingen (San Diego, CA) (cytochrome $c$ ), Biomol Research Laboratories (Plymouth, PA) (caspase-3, PARP), and Sigma (St. Louis, MO) ( $\alpha$-tubulin). Monoclonal (Clone IID8) and polyclonal SERCA2 antibodies were kindly provided by Dr. F. Wuytack (Division of Physiology, KULeuven, Belgium). The LC3 antibody was a kind gift from Dr. W. Martinet (Div. Pharmacology, University of Antwerp, Belgium). Horseradish peroxidaseconjugated secondary antibodies were obtained from DAKO (Glomstrup, Denmark). Trypan blue, Hoechst 33342, wortmannin, MG132, and 3-(4,5-dimethylthiazol-2-yl)-MTT were purchased from Sigma (St. Louis, MO). L-Histidine was from Fluka Chemie (Buchs, Switzerland). MitoTracker Red CMXRos, LysoTracker Green DND-26, ER-Tracker Blue-White DPX, and Indo-1-AM were purchased from Molecular Probes (Eugene, OR). z-DEVD-fmk was obtained from Bachem (Weil am Rhein, Germany). The murine embryonic fibroblasts (MEFs; wild-type [WT], $\mathrm{Bax}^{-/-} \mathrm{Bak}^{-/-}$double-knockout [DKO], $\mathrm{Bax}^{-1-} \mathrm{Bak}^{-1-}$ DKO reexpressing mtBAX [DKO-mtBAX], and $\mathrm{Bax}^{-1-} \mathrm{Bak}^{-1-}$ DKO overexpressing SERCA2 [DKO-SERCA]) were a kind gift from Dr. S. J. Korsmeyer (Dana-Farber Cancer Institute, Harvard Medical School, Boston, MA).

\section{Cell culture}

HeLa cells (human cervix carcinoma cells), obtained from American Type Culture Collection (ATCC), and WT and $\mathrm{Bax}^{-1-} \mathrm{Bak}^{-1-}$ DKO MEFs were cultured in Dulbecco's modified Eagle's medium (DMEM) containing L-glutamine (2 mM), penicillin (100 IU/ml), streptomycin (100 $\mu \mathrm{g} / \mathrm{ml}$ ), and $10 \%$ fetal calf serum. For DKO-mtBAX or DKO-SERCA MEFs, $2 \mu \mathrm{g} / \mathrm{ml}$ puromycin (Invivogen, San Diego, CA) was added to complete DMEM. Mock-transfected HeLa cells (Neo) and HeLa cells overexpressing GPx4 were cultured in complete DMEM containing

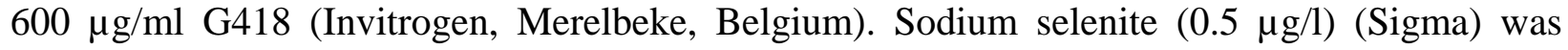
additionally added for culture of HeLa GPx4 cells. Overexpression of GPx4 in the cells was determined with quantitative RR-PCR analysis.

\section{Cell photosensitization}

HeLa cells were preincubated with $125 \mathrm{nM}$ hypericin for $16 \mathrm{~h}$ in subdued light conditions $(<1$ $\mu \mathrm{W} / \mathrm{cm}^{2}$ ), followed by irradiation in DMEM (PDT-treated). WT and DKO MEFs were incubated with either $1 \mu \mathrm{M}$ or $200 \mathrm{nM}$ hypericin for $2 \mathrm{~h}$ in serum-free DMEM, followed by replacement of the cells in complete DMEM. After incubation with hypericin, MEFs were checked by FACS analysis for hypericin (red) fluorescence intensity, ensuring equal intracellular hypericin concentrations in WT, DKO, DKO-SERCA, and DKO-mtBAX MEFs. Cell culture plates were placed on a plastic diffuser sheet above a set of seven L18W30 fluorescent lamps (Osram) as described previously (22). The fluence rate of the lamps was $4.5 \mathrm{~mW} / \mathrm{cm}^{2}$ as measured with an IL 1400 radiometer (International Light, Newburyport, MA). 


\section{Intracellular hypericin localization}

HeLa cells were incubated for $16 \mathrm{~h}$ with $0.5 \mu \mathrm{M}$ hypericin before incubation for 30 min with 500 nM Rhodamine 123 or $500 \mathrm{nM}$ ER-Tracker Blue-White DPX or 1 min with $1 \mu \mathrm{M}$ LysoTracker Green DND-26 at $37^{\circ} \mathrm{C}$. After washing, the cells were analyzed for (co)localization by confocal microscopy (LSM 150 META, Carl Zeiss, Göttingen, Germany) using a magnification of $\times 63$. Pictures were analyzed using LSM5 software 3.2.

\section{$\left[\mathrm{Ca}^{2+}\right]_{\text {cyt }}$ measurements with Indo-1}

Single-cell $\left[\mathrm{Ca}^{2+}\right]_{\mathrm{cyt}}$ measurements using a laser-scanning confocal fluorescence microscope (MRC-1024UV, Bio-Rad, Hercules, CA) coupled to an inverted epifluorescence microscope (Nikon Diaphot-TMD-EF) were performed as described previously (23). HeLa cells were incubated for $16 \mathrm{~h}$ with $125 \mathrm{nM}$ or $300 \mathrm{nM}$ hypericin as indicated, washed with a modified Krebs solution (135 mM NaCl, $5.9 \mathrm{mM} \mathrm{KCl,} 1.5 \mathrm{mM} \mathrm{CaCl}_{2}, 1.2 \mathrm{mM} \mathrm{MgCl}_{2}, 11.6 \mathrm{mM} \mathrm{HEPES}, 11.5$ $\mathrm{mM}$ glucose, $\mathrm{pH}$ 7.3), and then incubated with $5 \mu \mathrm{M}$ Indo-1-AM for $30 \mathrm{~min}$ at room temperature. After washing and further incubation in modified Krebs solution for 1-2 h, Indo-1 was excited at $363 \mathrm{~nm}$ and emission was collected at $405 \mathrm{~nm}$ and $480 \mathrm{~nm}$. The results are presented as the ratio of emitted fluorescence.

\section{Preparation of cell extracts and Western blotting}

Total cell lysates and cytosolic fractions for cytochrome $c$ analysis were prepared as previously described (22) at indicated time points following irradiation. Samples were then prepared for SDS-PAGE and Western blotting as previously described (24).

\section{Flow cytometric analysis of annexin V-FITC}

Cells were collected at an indicated time point after photosensitization. Annexin V-FITC was measured using the BD ApoAlert Annexin V-FITC Apoptosis Kit (BD Biosciences Clontech, Palo Alto, CA) according to the manufacturer's protocol. After annexin V-FITC (0.02 $\mu \mathrm{g} / \mathrm{ml})$ incubation, cells were analyzed for green fluorescence at 505-545 nm with a Coulter Epics XL Flow Cytometer (Beckman Coulter, Miami, FL). Data analysis was performed using Expo32 v1.2 software.

\section{Lysosomal membrane stability}

The stability of lysosomal membranes was analyzed by comparing uptake of LysoTracker Green DND-26 in untreated vs. PDT-treated cells as described for the acridine orange uptake method (25). After PDT treatment, HeLa cells were incubated with 75 nM LysoTracker Green DND-26 for $1 \mathrm{~h}$ and analyzed for green fluorescence by fluorescence microscopy (Axioskop 2 plus fluorescence microscope, Carl Zeiss).

\section{Transfection with organelle targeted aequorins and aequorin measurements}

HeLa cells were grown on $18 \mathrm{~mm}$ coated coverslips and transiently transfected with different chimeric aequorin cDNA constructs (erAEQ, cytAEQ, and mtAEQ) for $24 \mathrm{~h}$ before $16 \mathrm{~h}$ incubation with $125 \mathrm{nM}$ hypericin. The chimeric aequorin cDNA constructs were kindly donated 
by Dr. R. Rizzuto (University of Ferrara, Italy). After irradiation $\left(4 \mathrm{~J} / \mathrm{cm}^{2}\right)$, cells expressing erAEQ were reconstituted with $5 \mu \mathrm{M}$ coelenterazine $\mathrm{N}$ in modified Krebs-Ringer buffer (KRB) (125 mM NaCl, $5 \mathrm{mM} \mathrm{KCl,} 1 \mathrm{mM} \mathrm{MgSO}_{4}, 1 \mathrm{mM} \mathrm{Na}_{2} \mathrm{PO}_{4}, 5.5 \mathrm{mM}$ glucose, and $20 \mathrm{mM}$ HEPES, pH 7.4), containing $5 \mu \mathrm{M}$ ionomycin and $0.6 \mathrm{mM}$ EGTA. Cells were then washed three times with KRB containing $1 \mathrm{mM}$ EGTA and 2\% (w/v) BSA and kept in KRB containing $1 \mathrm{mM}$ EGTA and $5 \mathrm{mM}$ ATP when placed in the perfusion chamber at $22^{\circ} \mathrm{C}$. erAEQ-transfected cells were permeabilized with $100 \mu \mathrm{M}$ digitonin before addition of $200 \mathrm{nM} \mathrm{Ca}^{2+}$ and $0.3 \mu \mathrm{M} \mathrm{InsP}_{3}$ to release ER-Ca ${ }^{2+}$. HeLa cells transfected with mtAEQ and cytAEQ were reconstituted with $5 \mu \mathrm{M}$ coelenterazine $\mathrm{W}$ in cell culture medium for $2 \mathrm{~h}$ at $37^{\circ} \mathrm{C}$ before measurement as previously described (26). Light emission was measured by a luminometer and calibrated in terms of $\left[\mathrm{Ca}^{2+}\right]$ as previously described (27).

\section{Transient transfection with GFP-BAX or GFP-LC3}

HeLa cells were transfected with GFP-BAX using FuGENE 6 transfection reagent (Roche Applied Science, Vilvoorde, Belgium) according to the manufacturer's protocol. After transfection, cells were incubated with $125 \mathrm{nM}$ hypericin for $16 \mathrm{~h}$, before photosensitization as described above. The GFP-BAX (GFP fused to the $\mathrm{NH}_{2}$ terminus of BAX) construct was kindly donated by Dr. R. J. Youle (Biochemistry Section, Surgical Neurology Branch, NINDS, National Institutes of Health, Bethesda, MD). $\mathrm{Bax}^{-1-} \mathrm{Bak}^{-1-}$ DKO MEFs $\left(1 \times 10^{6}\right)$ were transfected with GFP-LC3 using the Amaxa electroporation system according to the supplier's protocol (kit V, program U-20). The cells were incubated with $200 \mathrm{nM}$ hypericin for $2 \mathrm{~h}$, followed by photosensitization as described above. The GFP-LC3 construct was a kind gift from Dr. J. Debnath (Dept. Cell Biology, Harvard Medical School, Boston, MA).

\section{Nuclear fragmentation}

Cells were PDT-treated as described above, and at indicated time points after irradiation stained with Hoechst 3342. Apoptotic nuclei were analyzed as previously described (20).

\section{Cell viability assay}

Cell death was assessed by trypan blue uptake (0.1\% in PBS). Dead cells were counted in at least 5 microcopic fields with a minimum of 50 cells per field. Data are expressed as percentage of trypan blue-positive cells over the total number of cells. Cell viability was estimated by MTT metabolism as described previously (24).

\section{Caspase-3 activity measurement}

Cells were PDT-treated as described above and lyzed at indicated time points after irradiation. Caspase-3 activity was measured by the Colorimetric Caspase-3 Assay Kit (Sigma) according to the manufacturer's instructions.

\section{Transmission electron microscopy}

DKO MEFs were cultured on ACLAR sheets and PDT-treated as described above. Cultures were rinsed in serum-free medium and then fixed in buffered $6 \%$ glutardialdehyde solution at $4^{\circ} \mathrm{C}$. After they were washed in $0.1 \mathrm{M}$ PBS, cells were postfixed in $2 \% \mathrm{OsO}_{4}$ for $2 \mathrm{~h}$ and dehydrated 
in ascending concentrations of EtOH, followed by embedding in Araldite, using propylene oxide as an intermediate. After polymerization, blocks were cut on a Leica UCT ultramicrotome at 300 $\mathrm{nm}$ (semithin sectioning) and $70 \mathrm{~nm}$, and photomicrographs were taken in a Philips CM10 transmission electron microscope equipped with a SIS MegaView III digital camera.

\section{Statistical analysis}

Data points represent the mean \pm SD. Statistical analysis was performed by Student's $t$ test, with $P<0.05$ and $P<0.01$ as criteria of significance.

\section{RESULTS}

\section{Hypericin intracellular localization and organelle-mediated effects of PDT}

Since the subcellular localization of the sensitizer principally determines the primary targets of photodamage, we initially performed a colocalization analysis in HeLa cells loaded with hypericin $\left(\lambda_{\max }=595 \mathrm{~nm}\right)$ using Rhodamine-123, LysoTracker, and ER-Tracker to stain mitochondria, lysosomes, and the ER, respectively. As shown in Fig. 1, hypericin mainly colocalized with the ER and to a significant extent also with lysosomes, whereas it did not particularly accumulate in mitochondria. A similar colocalization was consistently found in other cells, such as the human bladder cancer T24 cells and MEFs (data not shown), indicating that hypericin intracellular localization is not cell type-specific.

As the ER is the main cellular store of $\mathrm{Ca}^{2+}$, we evaluated the effects of PDT on cytosolic $\mathrm{Ca}^{2+}$ levels by loading the cells with the UV-excitable fluorescent $\mathrm{Ca}^{2+}$ indicator Indo-1. Exposure of HeLa cells to hypericin-mediated photodynamic stress caused a rise in $\left[\mathrm{Ca}^{2+}\right]_{\text {cyt }}$ within minutes (Fig. 2A), with kinetics that depended on the concentration of hypericin used (125-300 nM). Addition of $2 \mathrm{mM}$ EGTA to chelate extracellular $\mathrm{Ca}^{2+}$ in the culture medium did not substantially alter the profile and kinetics of the early $\mathrm{Ca}^{2+}$ rise (data not shown), suggesting that the rapid rise in $\left[\mathrm{Ca}^{2+}\right]_{\text {cyt }}$ in response to PDT is due to the depletion of intracellular $\mathrm{Ca}^{2+}$ stores. Similar results were obtained in T24 cells and MEFs (data not shown), indicating that rapid rise in $\left[\mathrm{Ca}^{2+}\right]_{\mathrm{cyt}}$ is a general response to hypericin-PDT.

Since hypericin was found to colocalize with lysosomes and because of the reported susceptibility of these organelles to oxidative stress (28), we next evaluated the integrity of lysosomal membranes in PDT-treated cells by the uptake of LysoTracker Green DND-26. This dye consists of a fluorophore linked to a weak base, which enables preferential accumulation in acidic cellular compartments. As shown in Fig. 2B, the punctuate LysoTracker Green DND-26 fluorescence pattern exhibited upon excitation with blue light, indicating accumulation of the dye into lysosomes, was similar in untreated (containing hypericin but not irradiated) and PDTtreated cells, indicating that no substantial lysosomal leakage had occurred at that point after irradiation. Similar results were obtained using acridine orange to stain lysosomes (data not shown), thus supporting the concept that under these conditions photodynamic injury to lysosomal membranes did not result in major loss of their integrity.

Following the rise in $\left[\mathrm{Ca}^{2+}\right]_{\mathrm{cy}}$, the molecular events associated with the mitochondrial pathway of apoptosis became manifest. The proapoptotic BAX protein translocated to the mitochondria, 
as shown by immunocytochemistry (Fig. 3A) concomitantly with the efflux of cytochrome $c$ and processing of procaspase-3 (Fig. 3B), resulting in significant apoptotic cell death (Fig. 3 C).

In keeping with the results showing maintenance of lysosomal membrane integrity after PDT, cell-permeable inhibitors of lysosomal proteases such as pepstatin A (cathepsin D), z-FA-fmk (cathepsin B and L), and E-64d (cathepsin B, H, L), used in a broad range of concentrations, did not influence either mitochondrial cytochrome $c$ release or overall PDT-induced cell death (data not shown).

\section{PDT-induced photodamage of the SERCA2 pump deregulates ER-Ca ${ }^{2+}$ homeostasis}

We next monitored changes in intracellular $\mathrm{Ca}^{2+}$ levels in response to PDT by targeting the aequorin $\mathrm{Ca}^{2+}$ photoreporter (26) to the ER lumen (erAEQ), cytosol (cytAEQ), and mitochondria (mtAEQ). HeLa cells were transfected with the different targeted aequorin chimera constructs for $24 \mathrm{~h}$, uploaded with hypericin, and subsequently irradiated $\left(4 \mathrm{~J} / \mathrm{cm}^{2}\right)$ before organellar $\mathrm{Ca}^{2+}$ levels were analyzed for aequorin luminescence (see Materials and Methods).

The steady-state $\left[\mathrm{Ca}^{2+}\right]_{\mathrm{ER}}$ in permeabilized cells exposed to $200 \mathrm{nM}$ free $\left[\mathrm{Ca}^{2+}\right]$ was drastically reduced (from $276 \pm 14 \mu \mathrm{M}$ to $122 \pm 27 \mu \mathrm{M}$ ) in the PDT-treated cells (Fig. 4A, left panel). Consequently, histamine-dependent $\left[\mathrm{Ca}^{2+}\right]_{\mathrm{cyt}}$ elevations were drastically blunted in the PDTtreated cells (Fig. 4A, middle panel). Secondary to the PDT-induced deregulation of ER-Ca ${ }^{2+}$ homeostasis, in the PDT-treated cells histamine-stimulation did not evoke any measurable $\left[\mathrm{Ca}^{2+}\right]_{\text {mit }}$ transients as typically observed in untreated cells (Fig. $4 A$, right panel), where $\mathrm{Ca}^{2+}$ uptake by the mitochondria in close contact with the ER participates in the regulation of the shape and amplitude of cytosolic $\mathrm{Ca}^{2+}$ transients (29).

Based on the evidence that PDT causes profound perturbations in the ER-Ca ${ }^{2+}$ homeostasis, we next evaluated the possibility that the sarco(endo)plasmic-reticulum $\mathrm{Ca}^{2+}$-ATPase (SERCA) pump could be a direct target of the oxidative stress generated by PDT. The SERCA pump couples ATP hydrolysis to $\mathrm{Ca}^{2+}$ transport from the cytosol across the ER membrane, which is essential to maintain the physiological level of resting $\left[\mathrm{Ca}^{2+}\right]_{\mathrm{ER}}$ three to four orders of magnitude higher than the $\left[\mathrm{Ca}^{2+}\right]_{\mathrm{cyt}}(30)$.

A drastic drop in protein levels of the native $100 \mathrm{kDa}$ SERCA2 as observed on Western blots occurred immediately after exposure of HeLa cells, T24 cells (unpublished results), and MEFs to PDT and was largely prevented by the addition of the ${ }^{1} \mathrm{O}_{2}$ quencher L-histidine (Fig. $4 \mathrm{~B}$ ).

Treatment of the cells with staurosporine, an apoptotic agent that does not cause direct oxidative stress, did not affect SERCA2 protein levels. In addition, caspase antagonists or the proteasome inhibitor MG132 did not prevent loss of the native SERCA2 protein levels after PDT (data not shown). These results indicate that SERCA2 photodamage is a specific ROS-mediated event, occurring immediately after photoirradiation in all cell lines examined, and not a secondary effect of caspase activation. They also suggest that the loss of the native $100 \mathrm{kDa}$ SERCA2 protein observed on Western blots is not due to removal of photodamaged protein by the proteasome, but rather to a photochemical modification of the native SERCA2 protein.

The highly reactive ${ }^{1} \mathrm{O}_{2}$ generated by PDT could cause peroxidation of ER membrane phospholipids, which in turn may lead to damage to proteins in their close proximity. 
Consistently, overexpression of the hydroperoxide-detoxyfying selenoenzyme glutathione peroxidase (GPx4), which removes phospholipid hydroperoxides in cellular membranes (31), also conferred protection from PDT-mediated SERCA2 protein loss (Fig. 4B).

No significant changes in Ins $\mathrm{P}_{3} \mathrm{R}$ protein levels after PDT were observed (data not shown), and maintenance of $\mathrm{InsP}_{3} \mathrm{R}$ function is also confirmed by the observation that agonist-stimulated ER-

$\mathrm{Ca}^{2+}$ release amounted to $\sim 40 \%$ of the steady-state $\left[\mathrm{Ca}^{2+}\right]_{\mathrm{ER}}$ in both untreated and PDT-treated cells (Fig. 4A).

We assumed that if the dramatic SERCA2 posttranslational modification induced by hypericinPDT was directly responsible for ER-Ca ${ }^{2+}$ depletion, then preserving SERCA2 in its native conformation by antioxidants should also preserve ER- $\mathrm{Ca}^{2+}$ stores after PDT. Consistent with this hypothesis, L-Histidine not only preserved SERCA2 protein levels after PDT but also restored ER-Ca ${ }^{2+}$ refilling after exposure of the permeabilized cells to $200 \mathrm{nM}$ free $\mathrm{Ca}^{2}$ (Fig. 4C).

All together, these observations show that SERCA2 is a specific and highly sensitive target of PDT and that preventing the functional loss of native SERCA2 proteins restores the capability of the ER to maintain $\left[\mathrm{Ca}^{2+}\right]_{\mathrm{ER}}$ in PDT-treated cells, thus establishing a functional link between SERCA2 photodamage and loss of ER-Ca ${ }^{2+}$ homeostasis.

\section{PDT-induced SERCA2 damage and loss of $\mathrm{Ca}^{2+}$ homeostasis trigger cell death}

We next examined whether maintaining SERCA2 levels by increasing the cellular antioxidant capacity could provide protection against PDT-induced cell death. As the intrinsic apoptotic pathway is supposed to depend upon the activation and translocation of BAX from the cytosol to the mitochondrial membrane, HeLa cells were transfected with a GFP-BAX fusion protein to monitor the kinetics of BAX redistribution in PDT-treated cells. Incubation with L-histidine before irradiation significantly counteracted the PDT-induced accumulation of cells exhibiting the punctuate pattern of GFP-BAX distribution (Fig. 5A), indicating BAX translocation to mitochondria, which was also confirmed by Western blotting of the cytosolic fraction from the treated cells (data not shown). Increasing the antioxidant capacity of cells either pharmacologically (Fig. 5A, $\underline{5 C}$ ) or genetically by overexpressing GPx4 (Fig. 5B) also retarded the acquisition of apoptotic parameters downstream of BAX activation such as cytochrome $c$ release, drop of $\Delta \Psi_{\mathrm{m}}$ (data not shown), caspase-3 activation and PARP cleavage, and overall cell death (Fig. 5C). Note that the protective effect of these antioxidants against cell killing declined with time as did the effect on the SERCA2 protein levels (Fig. 4B), strengthening the link between SERCA2 down-modulation and cell death.

Intriguingly, pretreatment of the cells with the cell-permeable $\mathrm{Ca}^{2+}$ chelator BAPTA-AM, resulting in the complete buffering of the cytosolic $\mathrm{Ca}^{2+}$ rise, did not prevent PDT-induced apoptosis (data not shown) as also reported in other studies $(15,32-34)$ or using EGTA as $\mathrm{Ca}^{2+}$ chelator (29). 


\section{BAX and BAK are necessary for the induction of apoptosis but are dispensable for the overall PDT-mediated cell death}

Recent findings indicate that antiapoptotic BCL-2 protects cells from stress-induced apoptosis by reducing the resting $\left[\mathrm{Ca}^{2+}\right]_{\mathrm{ER}}$ whereas proapoptotic BAX and BAK proteins are required to maintain ER-Ca ${ }^{2+}$ pool necessary for the induction of apoptosis by $\mathrm{Ca}^{2+}$-mobilizing stress signals $(30,35,36)$.

Consistently, $\mathrm{Bax}^{-1-} \mathrm{Bak}^{-1-}$ DKO MEFs display reduced resting $\left[\mathrm{Ca}^{2+}\right]_{\mathrm{ER}}$, and secondarily decreased $\mathrm{Ca}^{2+}$ uptake by mitochondria, thereby endowing DKO cells with prolonged resistance to apoptosis induced by a wide range of stimuli (9). This defect is corrected by the overexpression of SERCA2 (DKO-SERCA), which restores apoptosis in response to $\mathrm{Ca}^{2+}$ mobilizing stimuli, including oxidative stress, but not by the selective reexpression of BAX targeted to mitochondria (DKO-mtBAX), which instead resensitizes DKO cells to mitochondriausing apoptotic signals (9). These genetically manipulated cells enabled us to analyze the functional link between $\mathrm{Ca}^{2+}$ signaling and the BAX/BAK gateway at the mitochondria.

We first assessed the susceptibility of DKO cells to PDT-induced cell death using two concentrations of hypericin (200 $\mathrm{nM}$ and $1 \mu \mathrm{M}$ ) to evaluate possible dose-dependent cellular responses. SERCA2 photodamage occurred drastically and regardless of the PDT dose used in both WT and DKO cells (Fig. 6A); however, while the WT cells manifested the apoptotic hallmarks of cell death, the DKO cells displayed a clear protection against apoptosis, based on different criteria. As compared with WT cells, in response to PDT, they exhibited a clearcut reduction in nuclear fragmentation and absence of PARP cleavage (Fig. 6B). Moreover, the caspase inhibitor zDEVD-fmk reduced to a similar extent nuclear apoptosis and the loss of viability, as measured by trypan blue uptake, in the PDT-treated WT cells yet had no effect on the DKO cells (Fig. 6C). Albeit resistant to the caspase antagonist, DKO cells readily exhibited irreversible permeabilization of the plasma membrane (Fig. 6C), indicating that they were undergoing photokilling. Consistently, kinetic experiments showed that in response to PDT, DKO cells also displayed a loss of viability, as measured by the MTT assay (Fig. 6D).

Thus, while both PDT conditions (i.e., $200 \mathrm{nM}$ and $1 \mu \mathrm{M}$ hypericin) result in (functional) loss of the native SERCA2 protein, which likely defines the point of no return at the ER for cell killing, the WT cells die with the biochemical hallmarks of apoptosis and the DKO cells undergo nonapoptotic cell death.

Furthermore, analysis of procaspase-3 processing and actual DEVD-directed caspase activity assays showed that in response to PDT, caspase-3 was activated only in WT cells and in cells reexpressing mitochondria-targeted BAX (DKO-mtBAX) (Fig. 7A, $\underline{7 B}$ ). In strict contrast, in DKO and DKO-SERCA cells, there was no sign of procaspase-3 cleavage/activation, indicating that mitochondria-associated BAX is required for efficient effector caspase activation. This pattern was mirrored by the occurrence of cytochrome $c$ release and caspase-mediated PARP cleavage (data not shown) only in WT and DKO-mtBAX cells, but not in DKO or in DKOSERCA cells. 
As observed for hypericin-PDT, thapsigargin, a potent SERCA inhibitor inducing ER stress (3739), induced either a caspase-independent cell death pathway in $\mathrm{Bax}^{-1-} \mathrm{Bak}^{-1-}$-deficient MEFs or mitochondrial apoptosis in WT and DKO-mtBAX cells (data not shown).

This suggests that downstream of the ER stress caused either by inhibition (thapsigargin) or by severe posttranslational modification of the SERCA pump (PDT), both apoptotic and nonapoptotic cell death pathways can occur. In keeping with the triggering role of the ER stress in cell death in our paradigm, protection of the native SERCA proteins by antioxidants prevented PDT-induced cell death irrespective of the mechanism, that is, caspase-dependent or independent (Fig. 5C).

\section{$\mathrm{Bax}^{-/} \mathrm{Bak}^{-/-}$deficiency reveals an autophagic pathway of cell death}

We next analyzed at the morphological, ultrastructural, and biochemical levels what type of caspase-independent death pathway was initiated by PDT in the DKO cells.

While PDT (1 $\mu \mathrm{M}$ hypericin)-treated WT and DKO-mtBAX cells exhibited cellular shrinkage and membrane blebbing characteristic of apoptotic cell death, the DKO cells and more prominently the DKO-SERCA cells readily showed extensive cytosolic vacuolization (Fig. 8A), which was remarkably prevented by two inhibitors of phosphatidylinositol 3-kinase (PI3K), wortmannin (Fig. 8A), and LY-294002 (data not shown). In the presence of the PI3K inhibitors, the PDT-treated DKO cells appeared rounded, yet they did not show the typical morphology of apoptotic cells (Fig. 8A). Since class III PI3K has been found to be necessary for the sequestration of cytoplasmic material in autophagy (40), these observations suggested the induction of an autophagic pathway.

To substantiate this hypothesis, we examined PDT-treated DKO cells or untreated DKO cells at the ultrastructural level. Transmission electron microscopy (TEM) analysis revealed that after PDT, $\mathrm{Bax}^{-1-} \mathrm{Bak}^{-1-}$ cells displayed morphological features characteristic of early-stage macroautophagy (Fig. 8B). Compartmentalization of the cytoplasm by double-layered isolation membranes, often surrounding organelles like mitochondria (Fig. 8Bc), complete autophagosomes (Fig. 8Bd), and highly vacuolated cells (Fig. 8Be) were observed in PDTtreated DKO cells, whereas in untreated DKO cells, there were no signs of formation of autophagosome membranes (igi. 8Ba, $\underline{8 B b}$ ). TEM analysis also confirmed the absence of the hallmarks of apoptosis, like mitochondrial or nuclear alterations, in PDT-treated DKO cells.

When autophagy is stimulated, cytosolic microtubule-associated protein light-chain C (LC3 I), the mammalian ortholog of the yeast Atg8, is recruited and tightly bound upon processing (LC3 II) to the autophagosomal membranes (41). Therefore, to quantify the extent of autophagy in the DKO cells, we expressed the fluorescent GFP-LC3 fusion protein, a highly specific marker of mammalian autophagy, and estimated the time-dependent redistribution of GFP-LC3 from a diffused cytoplasmic pattern to a vacuolar/punctuate pattern, indicating its redistribution to preautophagosomal and autophagosomal membranes, following PDT with $200 \mathrm{nM}$ hypericin. At this lower PDT dose, autophagosome formation, as measured by counting the cells showing the characteristic vacuolar pattern of GFP-LC3, steadily increased with time (Fig. 8C), suggesting that the PDT intensity influences the kinetics at which the autophagic process proceeds. Moreover, upon PDT treatment of the DKO cells, we repeatedly detected on Western blots a 
conversion of the LC3 I (apparent mobility $18 \mathrm{kDa}$ ) into the autophagosome membraneassociated LC3 II form (apparent mobility $16 \mathrm{kDa}$ ) (Fig. 8C), which is a biochemical hallmark indicating autophagy activity.

\section{Inhibition of autophagy protects $\mathrm{Bax}^{-1-} \mathrm{Bak}^{-1-}$ DKO cells from photokilling}

We next endeavored to clarify whether autophagy in PDT-treated DKO cells was contributing to cell death. We first evaluated at the biochemical level whether the inhibitory action of wortmannin in DKO cells (Fig. 8A) reflected an inhibition of autophagy as documented in different studies $(40,42)$.

Although we found a basal level of LC3 II in untreated cells, PDT induced a marked accumulation of LC3 II in the DKO cells and more dramatically in the DKO-SERCA cells, whereas only a very small increase was observed in WT and DKO-mtBAX cells (Fig. 9B). The PI3K antagonist wortmannin maintained higher levels of the unprocessed LC3 I form in the DKO and DKO-SERCA cells, suggesting that this inhibitor interferes with the process of autophagosome formation in these cells, as also suggested by the morphological pattern shown in Fig. 8A.

Of note, pretreating the cells with wortmannin before irradiation with $200 \mathrm{nM}$ (data not shown) or $1 \mu \mathrm{M}$ hypericin markedly lowered the percentage of dead cells in DKO and DKO-SERCA cells (ig. $9 A)$, whereas it did not affect significantly the apoptotically dying WT and DKOmtBAX cells.

Wortmannin, however, did not prevent PDT-induced loss of the native SERCA2 protein (Fig. $\underline{9 C}$ ), indicating that this event is not the result of a proteolytic pathway activated by autophagy and thus positioning the protective action of PI3K inhibition in the DKO cells downstream of

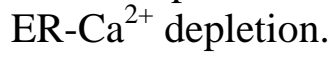

All together, these results suggest that irreversible photodamage to the ER in $\mathrm{Bax}^{{ }^{-1}} \mathrm{Bak}^{{ }^{-1}}$ DKO cells activates an autophagic-death pathway.

\section{PDT-induced autophagic cell death is not mediated by caspase inhibition}

To evaluate whether autophagy-induced cell death and the caspase-activation cascade are either two separate routes of cell demise or two signaling pathways that are subjected to a mutual control, we studied whether blocking DEVD-directed caspase activity in the PDT-treated WT cells would increase the level of autophagy. As the assessment of the LC3 II vs. LC3 I ratio by immunoblotting has been shown to correlate well with the number of autophagosomes formed and to provide an estimate of the abundance of autophagy $(41,43)$, we evaluated the effects of caspase or autophagy antagonists on this PDT-induced process in either WT or DKO cells.

Inhibition of DEVD-directed caspase activity, a biochemical hallmark of apoptosis, in PDTtreated WT cells by zDEVD-fmk completely abolished caspase-3 activity (data not shown), but hardly altered the LC3 II/LC3 I ratio in WT as well as in DKO cells (Fig. 10A).

Inhibition of autophagy-induced cell death by wortmannin reduced the LC3 II/LC3 I ratio (Fig. $\underline{10 A}$ ) in the PDT-treated DKO cells, whereas it did not alter either the level of active caspase-3 in 
the WT cells (Fig. 10B) nor its lethal effect, regardless of the PDT dose used (see also Fig. 9A). On the other hand, wortmannin did not induce caspase-3 activity in PDT-treated DKO cells, indicating again the strict requirement of multidomain BAX/BAK proteins for this process.

All together, these data suggest that PDT-induced autophagy in MEFs is not merely a consequence of the inhibition of the effector caspases and that caspase-mediated apoptosis is not affected by the inhibition of autophagy-induced cell death.

\section{DISCUSSION}

In the present study, we establish important features that single out cell death mechanisms induced by PDT. First, we show that in response to hypericin-based PDT, immediate photodamage of the SERCA2 pump and consequent depletion of ER-Ca ${ }^{2+}$ stores commits cells to death, and second, that deficiency in multidomain BAX and BAK proteins shifts the cell death modality from type 1, apoptosis, to type 2, autophagy (see Fig. 11).

Light activation of the ER-localizing hypericin leads to a fast rise in $\left[\mathrm{Ca}^{2+}\right]_{\mathrm{cyt}}$ associated with an immediate and ROS-mediated drop in the native SERCA2 protein levels as revealed on Western blots.

Consistent with our findings, photochemical-induced damage to SERCA2 and $\left[\mathrm{Ca}^{2+}\right]_{\mathrm{cyt}}$ elevations was also reported in studies using verteporfin-mediated PDT (15), arguing that this is a common event during PDT with ER-localizing photosensitizers. On the other hand, other photosensitizers localizing in mitochondrial membranes, including Pc4, have been shown to induce through a similar photochemical process an immediate and specific photodamage of the native mitochondrial BCL-2 protein (44), which is unaffected by hypericin-PDT (24). These observations strengthen the concept that, due to their colocalization in the ER membranes, SERCA2 is a specific phototarget of hypericin.

Direct measurements of steady-state $\left[\mathrm{Ca}^{2+}\right]_{\mathrm{ER}}$ using aequorin chimera targeted to the ER-lumen clearly show that after hypericin-PDT, the $\left[\mathrm{Ca}^{2+}\right]_{\mathrm{ER}}$ is drastically reduced. Importantly, preserving the functional native configuration of the SERCA2 protein by increasing the antioxidant capacity of the cells through pharmacological (L-histidine) or genetic (GPx4 expression) approaches (Fig. 4B) restores ER-Ca ${ }^{2+}$ levels (Fig. 4C) and impairs the acquisition of critical cell death parameters (e.g., BAX activation, cytochrome $c$ release, $\Delta \psi_{\mathrm{m}}$ drop, caspase-3 and PARP cleavage, permeabilization of plasma membrane). These observations coupled with the universal occurrence (found in all cells examined) and common fast kinetics (immediately after irradiation) of the SERCA2 photodamage (Fig. 4B), which by far preceded all the biochemical and morphological hallmarks of cell death (Fig. 5), support the argument that this is the most profound commitment point to cell death in our paradigm. Several studies have indeed reported that SERCA2 is rapidly inactivated by ROS (45-47) and inhibition of SERCA by oxidative stress or by thapsigargin, a potent inhibitor of this $\mathrm{Ca}^{2+}$-ATPase, induces apoptosis in different cellular models (33, 37, 38).

Our study reveals that downstream of SERCA2 photodamage and secondarily ER-Ca ${ }^{2+}$ depletion, two cell death pathways can be initiated, ensuring the elimination of the PDT-damaged cells. 
In cells expressing BAX and BAK, PDT rapidly engages the intrinsic apoptotic cell death program (Fig. 3, 5, ). This pathway is largely, but not completely, dependent on the mitochondrial-driven caspase activation cascade. As a matter of fact, PDT-induced apoptosis with different photosensitizers, including hypericin, has been shown to be only partially counteracted by caspase antagonists $(18,19)$ or caspase deficiency $(21)$, suggesting that besides cytochrome $c$ other apoptogenic factors, which utilize caspase-independent subroutines such as AIF $(18,19)$, are released from mitochondria and contribute to an apoptotic-like cell demise. Irrespective of the molecular identity of the apoptogenic factors released from mitochondria, this study convincingly shows that the BAX/BAK gateway at the mitochondria is a critical requisite for PDT-induced apoptosis. This is disclosed by the finding that while after PDT all the biochemical hallmarks of apoptosis are prevented in $\mathrm{Bax}^{-1-} \mathrm{Bak}^{-1-}$ DKO cells, the reexpression of mitochondria-targeted BAX is sufficient to resensitize these cells to caspase activation and apoptosis (ig. 7, $\underline{8})$. Since the DKO and DKO-SERCA cells differ in their steady-state $\left[\mathrm{Ca}^{2+}\right]_{\mathrm{ER}}$ (9) but not in their resistance to PDT-induced apoptosis (Fig. 7, ), it appears that downstream of the irreversible photodamage to SERCA2 and $\mathrm{ER}^{-\mathrm{Ca}^{2+}}$ emptying, $\mathrm{Ca}^{2+}$ uptake by the mitochondria per se is not sufficient to set apoptosis in motion. In agreement with this, neither the mitochondrial $\mathrm{Ca}^{2+}$ uniporter inhibitor Ru360 nor the permeability transition inhibitor CsA provides significant protection against PDT-induced cytochrome $c$ release and apoptosis in our system (unpublished results). The observation that in our study the $\mathrm{Ca}^{2+}$ chelator BAPTA-AM does not prevent PDT-induced apoptosis is intriguing albeit not uncommon (for a review, see ref 29). Some recent reports indicate that sustained ER depletion rather than the transient rise in $\left[\mathrm{Ca}^{2+}\right]_{\text {cyt }}$ triggers the apoptotic program $(32,34,39)$. Also, buffering of cytosolic $\mathrm{Ca}^{2+}$ by BAPTA-AM has been shown to be ineffective in blocking the redistribution of BAX from the cytosol to the mitochondria and apoptosis in conditions of ER-Ca ${ }^{2+}$ depletion (32). Hence, it is possible that sustained ER-Ca ${ }^{2+}$ depletion acts as the triggering event for BAX activation that is required to initiate mitochondrial apoptosis in PDT-treated cells.

Moreover, our results show that SERCA2 photodamage and consequent ER-Ca ${ }^{2+}$ depletion are sufficient to commit cells to death. Indeed, $\mathrm{Bax}^{-1-} \mathrm{Bak}^{-1-}$ DKO cells are resistant to PDT-induced apoptosis but die through a nonapoptotic program, with some necrotic-associated features such as absence of caspase signaling (Fig. 7A) and nuclear apoptosis (Fig. $6 B$ ) and a more pronounced plasma membrane permeabilization (Fig. 6C, $\underline{9 A}$ ), thus evidencing that the commitment point in PDT-induced cell death is upstream of BAX/BAK activation. In addition, DKO cells are completely insensitive to caspase antagonists (Fig. 6C), further demonstrating the fully caspaseindependent nature of the PDT-induced cell death modality in these cells. In our system, it seems unlikely that autophagy is driven by the mitochondrial alterations occurring during cell death, such as the opening of the permeability transition pore resulting in drop of the mitochondrial membrane potential, as recently reported in the study of Elmore et al. (48) or by a direct photodamage to the mitochondria. In fact, while SERCA2 photodamage occurs immediately after irradiation in all cells examined, cytochrome $c$ release and mitochondrial membrane depolarization are not events linked to cell killing in DKO cells where active autophagy is taking place. Moreover, as mentioned before, we do not have experimental evidence for a role of the MPT in our paradigm of cell death as HeLa or MEFs cells treated with CsA, a pharmacological inhibitor of the MPT, are not protected against photokilling (data not shown).

Our results are basically consistent with a previous report showing that in Bax-deficient cells exposed to PDT with the silicon-phthalocyanine (Pc4), key apoptotic events, including the 
release of cytochrome $c$ from mitochondria, loss of mitochondrial membrane potential, caspase activation, and nuclear fragmentation, are blocked, whereas the overall process of cell death is not affected (49). However, the modality of the cell death in the Pc4-PDT-treated cells was not explored.

In the present study, the demonstration of autophagic vesicles and autophagosomes by TEM and changes in the intracellular localization of GFP-LC3 as well as processing of LC3 I into the autophagosome-bound LC3 II (Fig. 8, 9) in DKO cells following PDT provide reliable evidence for the induction of autophagy after hypericin-PDT.

Autophagy, a major degradative pathway protecting mammalian cells from extracellular (e.g., nutrient deprivation, hypoxia, high temperature) and intracellular (e.g., accumulation of damaged or superfluous organelles and cytoplasmic components) stress conditions is a main form of programmed cell death in differentiation and development (43), and deregulation of autophagy has been proposed to play a role in certain pathologies, such as cancer and neurodegeneration (50). However, it is still controversial whether autophagy observed under different physiopathological settings actively contributes to cell death or represents a failed effort to preserve energy homeostasis and survival. Moreover, to what extent type 1, apoptosis, and type 2, autophagy, cell death engage separate pathways or share molecular (positive or negative) regulators is still unclear.

In line with the known requirement of class III PI3K for the sequestration of cytoplasmic material during authophagic cell death (40), PI3K inhibitors block both the extensive cytoplasmic vacuolization and biochemical hallmarks of autophagy induced in the DKO cells by PDT (Fig. 8, 9). In addition to that, pharmacological blockade of autophagy in DKO cells results in a significant reduction in photokilling (Fig. 9), suggesting that autophagy is a lethal pathway in our settings. The effect of wortmannin is specific inasmuch as it does not affect WT and DKO-mtBAX cells, in terms of caspase-activation and apoptotic cell death (i‥ 9, 10). On the other hand, the inhibition of DEVD-directed caspases, although not completely protective against photokilling for the reasons discussed above, is per se not sufficient to prompt autophagic cell death in the WT cells after PDT, at least not during the time course of our experiments. The fact that in our study autophagy as a death pathway can be specifically revealed by the ablation of the multidomain BAX and BAK proteins, which are strictly required for mitochondrial apoptosis, suggests that in WT cells other mitochondrial factors contributing to an apoptotic-like morphology can still overshadow autophagy-driven cell death in the presence of caspase inhibitors.

In keeping with this, recent studies underscore that the balance between antiapoptotic and proapoptotic BCL-2 family members functions as a rheostat not only in type 1 (apoptosis), but also in type 2 (autophagy) cell death. Shimizu and et al. (42) demonstrated that in response to classical mitochondria-using apoptotic stimuli, such as etoposide or staurosporine, cell death dependent on autophagy genes is induced by Bax/Bak deficiency and not by caspase inhibition or knock down. In addition, a recent study convincingly shows that BCL-2, by interacting with the autophagy gene beclin 1 , can suppress starvation-induced autophagy, whose nonphysiological levels and persistence ultimately cause cell death (51). 
In conclusion, our study provides evidence suggesting that the "point of no return" in the cell death program by hypericin-PDT consists of irreversible oxidative damage to the SERCA2 pump, a key ER $\mathrm{Ca}^{2+}$ regulator, with the consequent loss of the capability of storing $\mathrm{Ca}^{2+}$ ions and regulating $\mathrm{Ca}^{2+}$ fluxes within the cell. In the presence of multidomain proapoptotic BAX and BAK proteins, this pathway can be transduced by the mitochondrial apoptotic machinery. Under these conditions, autophagy is preempted by the BAX/BAK-mediated mitochondrial outer membrane permeabilization, which results in the release of caspase-activating factors and other destructive molecules causing apoptotic cell death. In the absence of BAX and BAK, the extensive damage to the ER sustains the autophagic process, which leads to the execution of the death program through a nonapoptotic pathway. Irrespective of the possibility that PDT-induced autophagy might be initiated as an attempt to remove an irreversibly damaged organelle, for example, the ER, and to preserve the cells from a metabolic collapse, this study reveals that excess levels of autophagy and its persistence leads to cell killing. For the future it will be important to assess whether autophagy is induced in vivo upon hypericin-based PDT of human cancers, where apoptotic signaling is often impaired, and whether instigation of autophagy by PDT adds value to its therapeutic potential.

\section{ACKNOWLEDGMENTS}

We thank Dr. R. J. Youle (NIH, Bethesda, MD) for kindly donating the GFP-BAX construct, Dr. R. Rizzuto (University of Ferrara, Italy) for the organelle-targeted aequorin constructs, Dr. F. Wuytack and Dr. J. B. Parys (Div. Physiology, K.U.Leuven, Belgium) for antibodies against SERCA2 and the Ins3PR, Dr. W. Martinet (Div. Pharmacology, University of Antwerp, Belgium) for the rat anti-LC3 antibody, and Dr. J. Debnath (Dept. Cell Biology, Harvard Medical School, Boston, MA) for the GFP-LC3 construct. We also acknowledge Dr. A. Vantieghem for help with Indo-1 experiments and M. Van de Putte for help with the fluorescent imaging analysis. We express our gratitude to An Snellinx for her excellent assistance with the EM preparations. We thank the Cell Imaging Core of the K.U.Leuven Impulsfinanciering Zware Apparatuur, for access to the multiphoton fluorescence microscope. This work was supported by

the Geconcerteerde Onderzoeksacties (GOA, from the KU.Leuven), the Interuniversitaire Attractiepolen (IAP, V/P12) of the Federal Belgian Government, and F.W.O grant G.0104.02.

\section{REFERENCES}

1. Dolmans, D. E., Fukumura, D., and Jain, R. K. (2003) Photodynamic therapy for cancer. Nat. Rev. Cancer 3, 380-387

2. Agostinis, P., Vantieghem, A., Merlevede, W., and de Witte, P. A. (2002) Hypericin in cancer treatment: more light on the way. Int. J. Biochem. Cell Biol. 34, 221-241

3. Chen, B., Roskams, T., Xu, Y., Agostinis, P., and de Witte, P. A. (2002) Photodynamic therapy with hypericin induces vascular damage and apoptosis in the RIF-1 mouse tumor model. Int. J. Cancer 98, 284-290

4. Lemasters, J. J., Qian, T., He, L., Kim, J. S., Elmore, S. P., Cascio, W. E., and Brenner, D. A. (2002) Role of mitochondrial inner membrane permeabilization in necrotic cell death, apoptosis, and autophagy. Antioxid. Redox Signal. 4, 769-781 
5. Chipuk, J. E., and Green, D. R. (2005) Do inducers of apoptosis trigger caspase-independent cell death? Nat. Rev. Mol. Cell Biol. 6, 268-275

6. Lockshin, R. A., and Zakeri, Z. (2004) Caspase-independent cell death? Oncogene 23, 2766-2773

7. Danial, N. N., and Korsmeyer, S. J. (2004) Cell death: critical control points. Cell 116, 205219

8. Wei, M. C., Zong, W. X., Cheng, E. H., Lindsten, T., Panoutsakopoulou, V., Ross, A. J., Roth, K. A., MacGregor, G. R., Thompson, C. B., and Korsmeyer, S. J. (2001) Proapoptotic BAX and BAK: a requisite gateway to mitochondrial dysfunction and death. Science 292, 727-730

9. Scorrano, L., Oakes, S. A., Opferman, J. T., Cheng, E. H., Sorcinelli, M. D., Pozzan, T., and Korsmeyer, S. (2003) BAX and BAK regulation of endoplasmic reticulum $\mathrm{Ca}^{2+}$ : a control point for apoptosis. Science 300, 135-139

10. Zong, W. X., Li, C., Hatzivassiliou, G., Lindsten, T., Yu, Q. C., Yuan, J., and Thompson, C. B. (2003) Bax and Bak can localize to the endoplasmic reticulum to initiate apoptosis. $J$. Cell Biol. 162, 59-69

11. Nutt, L. K., Chandra, J., Pataer, A., Fang, B., Roth, J. A., Swisher, S. G., O'Neil, R. G., and McConkey, D. J. (2002) Bax-mediated $\mathrm{Ca}^{2+}$ mobilization promotes cytochrome c release during apoptosis. J. Biol. Chem. 277, 20301-20308

12. Pinton, P., Ferrari, D., Magalhaes, P., Schulze-Osthoff, K., Di Virgilio, F., Pozzan, T., and Rizzuto, R. (2000) Reduced loading of intracellular $\mathrm{Ca}(2+)$ stores and downregulation of capacitative $\mathrm{Ca}(2+)$ influx in Bcl-2-overexpressing cells. J. Cell Biol. 148, 857-862

13. Orrenius, S., Zhivotovsky, B., and Nicotera, P. (2003) Regulation of cell death: the calciumapoptosis link. Nat. Rev. Mol. Cell Biol. 4, 552-565

14. Demaurex, N., and Distelhorst, C. (2003) Cell biology. Apoptosis-the calcium connection. Science 300, 65-67

15. Granville, D. J., Ruehlmann, D. O., Choy, J. C., Cassidy, B. A., Hunt, D. W. C., van Breemen, C., and McManus, B. M. (2001) Bcl-2 increases emptying of endoplasmic reticulum $\mathrm{Ca}^{2+}$ stores during photodynamic therapy-induced apoptosis. Cell Calcium 30, $343-350$

16. Inanami, O., Yoshito, A., Takahashi, K., Hiraoka, W., and Kuwabara, M. (1999) Effects of BAPTA-AM and forskolin on apoptosis and cytochrome c release in photosensitized Chinese hamster V79 cells. Photochem. Photobiol. 70, 650-655

17. Penning, L. C., Rasch, M. H., Ben-Hur, E., Dubbelman, T. M. A. R., Havelaar, A. C., Van der Zee, J., and Van Steveninck, J. (1992) A role for the transient increase of cytoplasmic 
free calcium in cell rescue after photodynamic treatment. Biochim. Biophys. Acta 1107, 255-260

18. Oleinick, N. L., Morris, R. L., and Belichenko, I. (2002) The role of apoptosis in response to photodynamic therapy: what, where, why, and how. Photochem. Photobiol. Sci. 1, 1-21

19. Agostinis, P., Buytaert, E., Breyssens, H., and Hendrickx, N. (2004) Regulatory pathways in photodynamic therapy induced apoptosis. Photochem. Photobiol. Sci. 3, 721-729

20. Assefa, Z., Vantieghem, A., Declercq, W., Vandenabeele, P., Vandenheede, J. R., Merlevede, W., de Witte, P., and Agostinis, P. (1999) The activation of the c-Jun N-terminal kinase and p38 mitogen-activated protein kinase signaling pathways protects HeLa cells from apoptosis following photodynamic therapy with hypericin. J. Biol. Chem. 274, 87888796

21. Whitacre, C. M., Satoh, T. H., Xue, L., Gordon, N. H., and Oleinick, N. L. (2002) Photodynamic therapy of human breast cancer xenografts lacking caspase-3. Cancer Lett. 179, 43-49

22. Vantieghem, A., Assefa, Z., Vandenabeele, P., Declercq, W., Courtois, S., Vandenheede, J. R., Merlevede, W., de Witte, P. A., and Agostinis, P. (1998) Hypericin-induced photosensitization of HeLa cells leads to apoptosis or necrosis. Involvement of cytochrome c and procaspase-3 activation in the mechanism of apoptosis. FEBS Lett. 440, 19-24

23. Missiaen, L., De Smedt, H., Parys, J. B., Oike, M., and Casteels, R. (1994) Kinetics of empty-store activated $\mathrm{Ca}^{2+}$. J. Biol. Chem. 269, 5917-5823

24. Vantieghem, A., Xu, Y., Assefa, Z., Piette, J., Vandenheede, J. R., Merlevede, W., de Witte, P. A. M., and Agostinis, P. (2002) Phosphorylation of Bcl-2 in G2/M phase-arrested cells following photodynamic therapy with hypericin involves a CDK1-mediated signal and delays the onset of apoptosis. J. Biol. Chem. 277, 37718-37731

25. Zdolsek, J. M., Olsson, G. M., and Brunk, U. T. (1990) Photooxidative damage of lysosomes of cultured macrophages by acridine orange. Photochem. Photobiol. 51, 67-76

26. Chiesa, A., Rapizzi, E., Tosello, V., Pinton, P., de Virgilio, M., Fogarty, K. E., and Rizzuto, R. (2001) Recombinant aequorin and green fluorescent protein as valuable tools in the study of cell signalling. Biochem. J. 355, 1-12

27. Rizzuto, R., Brini, M., Bastianutto, C., Marsault, R., and Pozzan, T. (1995) Photoproteinmediated measurement of calcium ion concentration in mitochondria of living cells. Methods Enzymol. 260, 417-428

28. Nilsson, E., Ghassemifar, R., and Brunk, U. T. (1997) Lysosomal heterogeneity between and within cells with respect to resistance against oxidative stress. Histochem. J. 29, 857-865

29. Rizzuto, R., Duchen, M. R., and Pozzan, T. (2004) Flirting in little space: the ER/mitochondria $\mathrm{Ca}^{2+}$ liaison. Sci. STKE 215, re1 10.1126/stke.2152004re1 
30. Berridge, M. J., Bootman, M. D., and Roderick, H. L. (2003) Calcium signalling: dynamics, homeostasis and remodelling. Nat. Rev. Mol. Cell Biol. 4, 517-529

31. Kuhn, H., and Borchert, A. (2002) Regulation of enzymatic lipid peroxidation: the interplay of peroxidizing and peroxide reducing enzymes. Free Radic. Biol. Med. 33, 154-172

32. Pan, Z., Bhat, M. B., Nieminen, A. L., and Ma, J. (2001) Synergistic movements of $\mathrm{Ca}^{2+}$ and Bax in cells undergoing apoptosis. J. Biol. Chem. 276, 32257-32263

33. Nguyen, H. N., Wang, C., and Perry, D. C. (2002) Depletion of intracellular calcium stores is toxic to SH-SY5Y neuronal cells. Brain Res. 924, 159-166

34. Pan, Z., Damron, D., Nieminen, A. L., Bhat, M. B., and Ma, J. (2000) Depletion of intracellular $\mathrm{Ca}^{2+}$ by caffeine and ryanodine induces apoptosis of Chinese hamster ovary cells transfected with ryanodine receptor. J. Biol. Chem. 275, 19978-19984

35. Nutt, L. K., Pataer, A., Pahler, J., Fang, B., Roth, J., McConkey, D. J., and Swisher, S. G. (2002) Bax and Bak promote apoptosis by modulating endoplasmic reticular and mitochondrial $\mathrm{Ca}^{2+}$ stores. J. Biol. Chem. 277, 9219-9225

36. Oakes, S. A., Opferman, J. T., Pozzan, T., Korsmeyer, S. J., and Scorrano, L. (2003) Regulation of endoplasmic reticulum $\mathrm{Ca}^{2+}$ dynamics by proapoptotic BCL-2 family members. Biochem. Pharmacol. 66, 1335-1340

37. Yamaguchi, H., Bhalla, K., and Wang, H. G. (2003) Bax plays a pivotal role in thapsigargininduced apoptosis of human colon cancer HCT116 cells by controlling Smac/Diablo and Omi/HtrA2 release from mitochondria. Cancer Res. 63, 1483-1489

38. Wei, H., Wei, W., Bredesen, D. E., and Perry, D. C. (1998) Bcl-2 protects against apoptosis in neuronal cell line caused by thapsigargin-induced depletion of intracellular calcium stores. J. Neurochem. 70, 2305-2314

39. Chae, H. J., Chae, S. W., Weon, K. H., Kang, J. S., and Kim, H. R. (1999) Signal transduction of thapsigargin-induced apoptosis in osteoblast. Bone 25, 453-458

40. Petiot, A., Ogier-Denis, E., Blommaart, E. F., Meijer, A. J., and Codogno, P. (2000) Distinct classes of phosphatidylinositol 3 '-kinases are involved in signaling pathways that control macroautophagy in HT-29 cells. J. Biol. Chem. 275, 992-998

41. Kabeya, Y., Mizushima, N., Ueno, T., Yamamoto, A., Kirisako, T., Noda, T., Kominami, E., Ohsumi, Y., and Yoshimori, T. (2000) LC3, a mammalian homologue of yeast Apg8p, is localized in autophagosome membranes after processing. EMBO J. 19, 5720-5728

42. Shimizu, S., Kanaseki, T., Mizushima, N., Mizuta, T., Arakwa-Kobayashi, S., Thompson, C. B., and Tsujimoto, Y. (2004) Role of Bcl-2 family proteins in a non-apoptotic programmed cell death dependent on autophagy genes. Nat. Cell Biol. 6, 1221-1228 
43. Gozuacik, D., and Kimchi, A. (2004) Autophagy as a cell death and tumor suppressor mechanism. Oncogene 23, 2891-2906

44. Usuda, J., Chiu, S. M., Murphy, E. S., Lam, M., Nieminen, A. L., and Oleinick, N. L. (2003) Domain-dependent photodamage to Bcl-2. A membrane anchorage region is needed to form the target of phthalocyanine photosensitization. J. Biol. Chem. 278, 2021-2029

45. Kaplan, P., Babusikova, E., Lehotsky, J., and Dobrota, D. (2003) Free radical-induced protein modification and inhibition of $\mathrm{Ca}^{2+}$-ATPase of cardiac sarcoplasmic reticulum. Mol. Cell. Biochem. 248, 41-47

46. Viner, R. I., Williams, T. D., and Schoneich, C. (1999) Peroxynitrite modification of protein thiols: oxidation, nitrosylation, and S-glutathiolation of functionally important cysteine residue(s) in the sarcoplasmic reticulum Ca-ATPase. Biochemistry 38, 12408-12415

47. Squier, T. C., and Bigelow, D. G. (2000) Protein oxidation and age-dependent alterations in calcium homeostasis. Front. Biosci. 5, 504-526

48. Elmore, S. P., Qian, T., Grissom, S. F., and Lemasters, J. J. (2001) The mitochondrial permeability transition initiates autophagy in rat hepatocytes. FASEB J. 15, 2286-2297

49. Chiu, S. M., Xue, L. Y., Usuda, J., Azizuddin, K., and Oleinick, N. L. (2003) Bax is essential for mitochondrion-mediated apoptosis but not for cell death caused by photodynamic therapy. Br. J. Cancer 89, 1590-1597

50. Shintani, T., and Klionsky, D. J. (2004) Autophagy in health and disease: a double edged sword. Science 306, 990-995

51. Pattingre, S., Tassa, A., Qu, X., Garuti, R., Liang, X. H., Mizushima, N., Packer, M., Schneider, M. D., and Levine, B. (2005) Bcl-2 antiapoptotic proteins inhibit beclin 1dependent autophagy. Cell 122, 927-939

52. Delaey, E. M., Vandenbogaerde, A. L., Agostinis, P., and De Witte, P. A. (1999) Confluence dependent resistance to photo-activated hypericin in HeLa cells. Int. J. Oncol. 14, 759-763

Received May 12, 2005; accepted December 9, 2005. 
Fig. 1

\section{ER-Tracker}

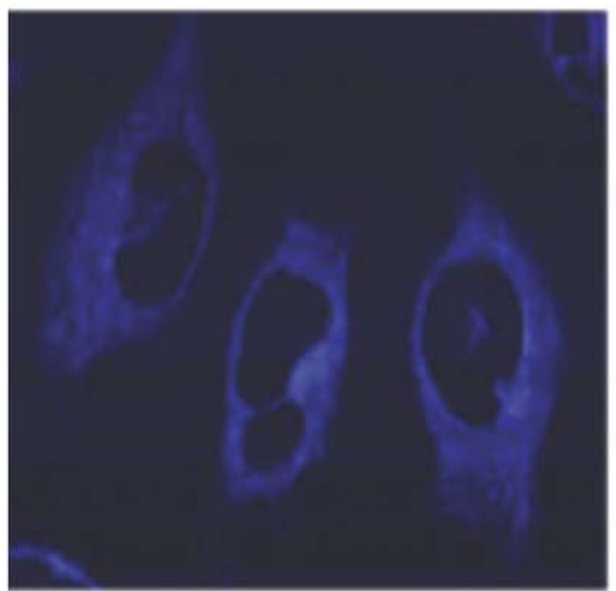

LysoTracker

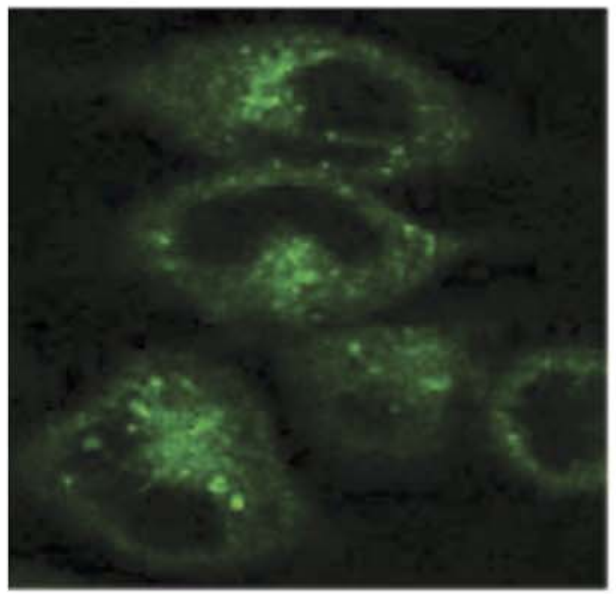

Rh123

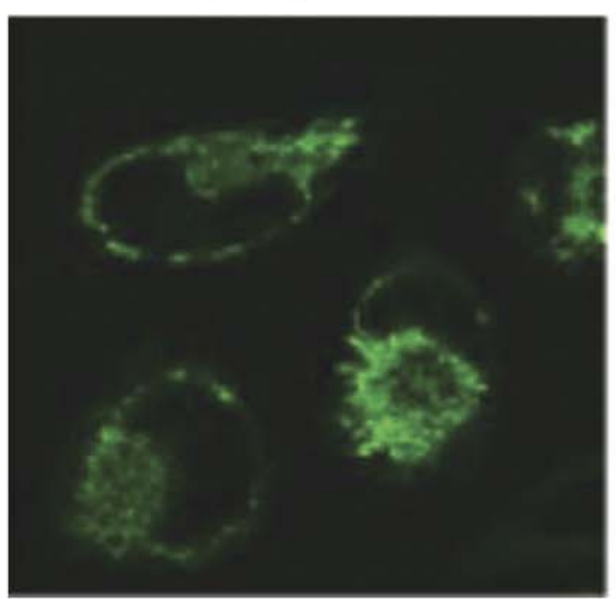

hypericin

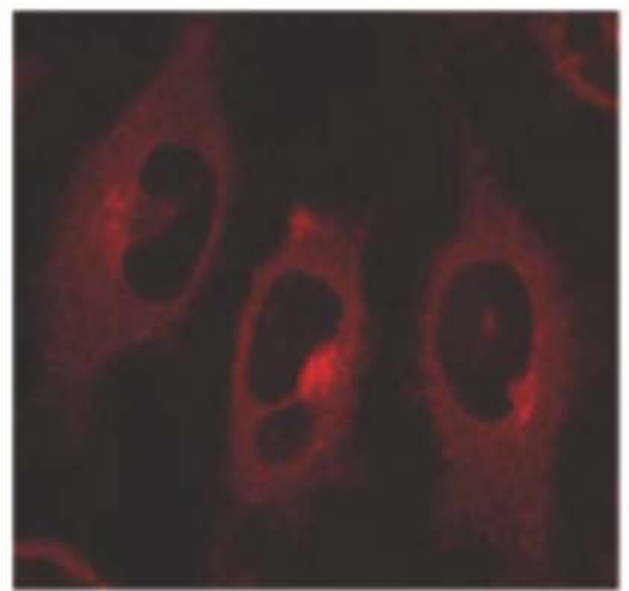

hypericin

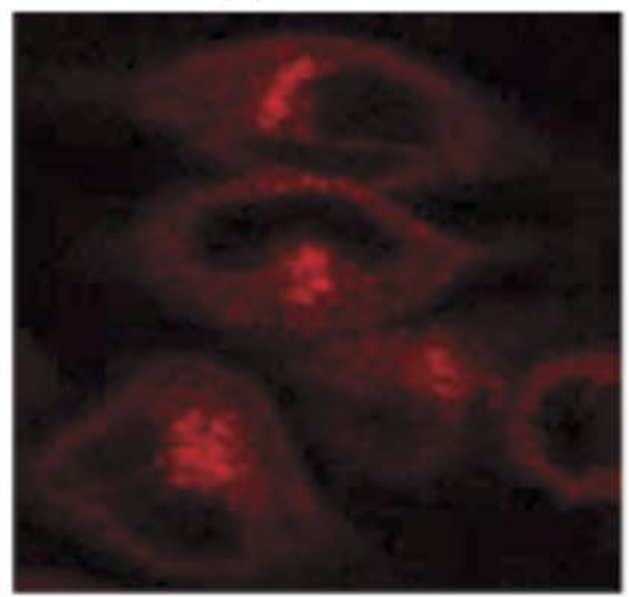

hypericin

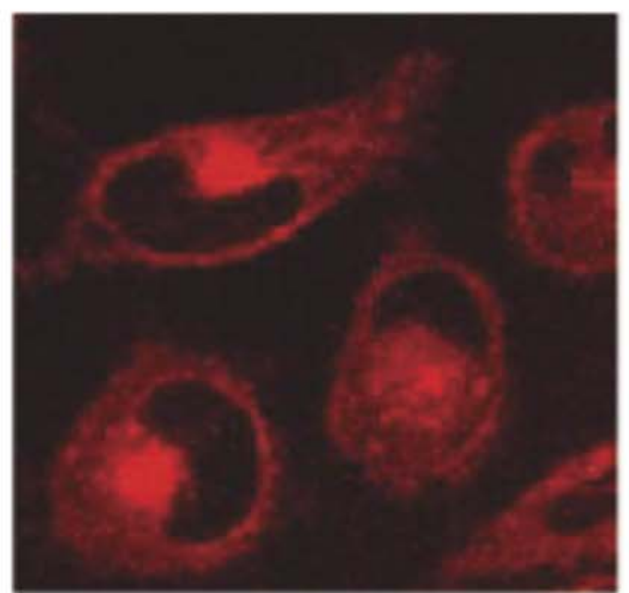

overlay

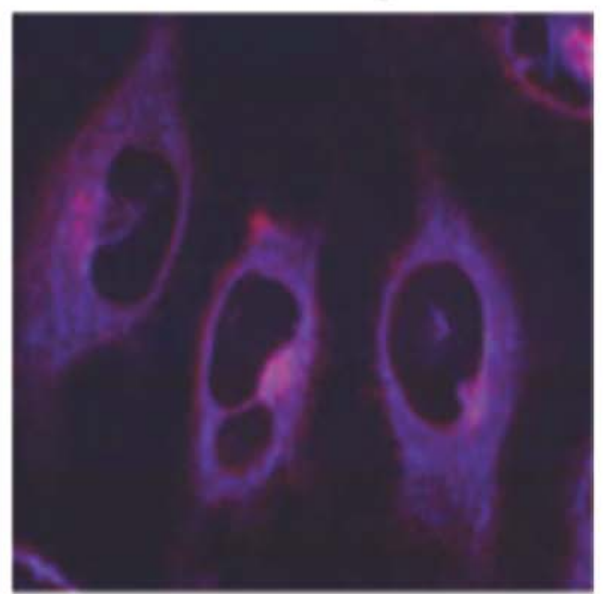

overlay

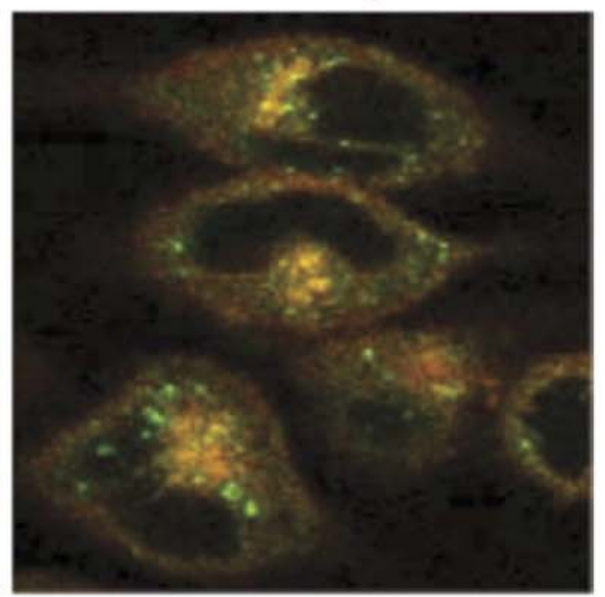

overlay

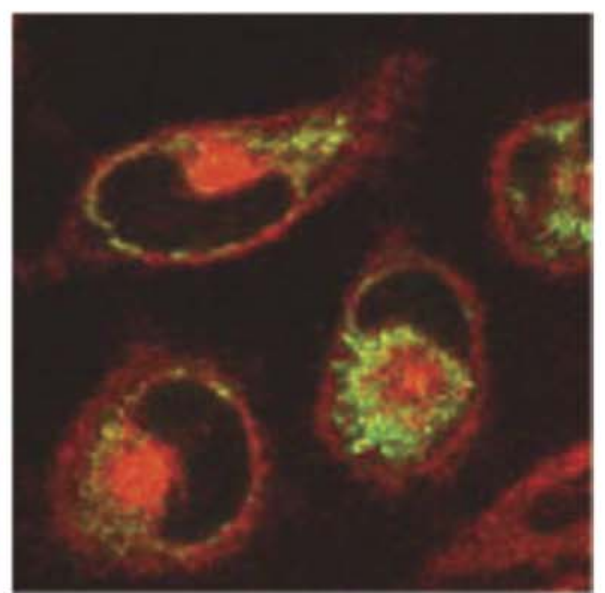

Figure 1. Hypericin localizes to ER and lysosomes in HeLa cells. Confocal microscopic analysis of HeLa cells incubated for $16 \mathrm{~h}$ with hypericin $(500 \mathrm{nM}$, red). The panels show staining with the ER-specific probe ER-Tracker Blue-White DPX (500 nM, blue), the lysosomal-specific probe LysoTracker Green DND-26 (1 $\mu \mathrm{M}$, green), and the mitochondrial dye Rhodamine 123 (500 nM, green). Merged fluorescence (purple for blue and red and yellow for green and red) indicating colocalization is shown on the right. 
Fig. 2
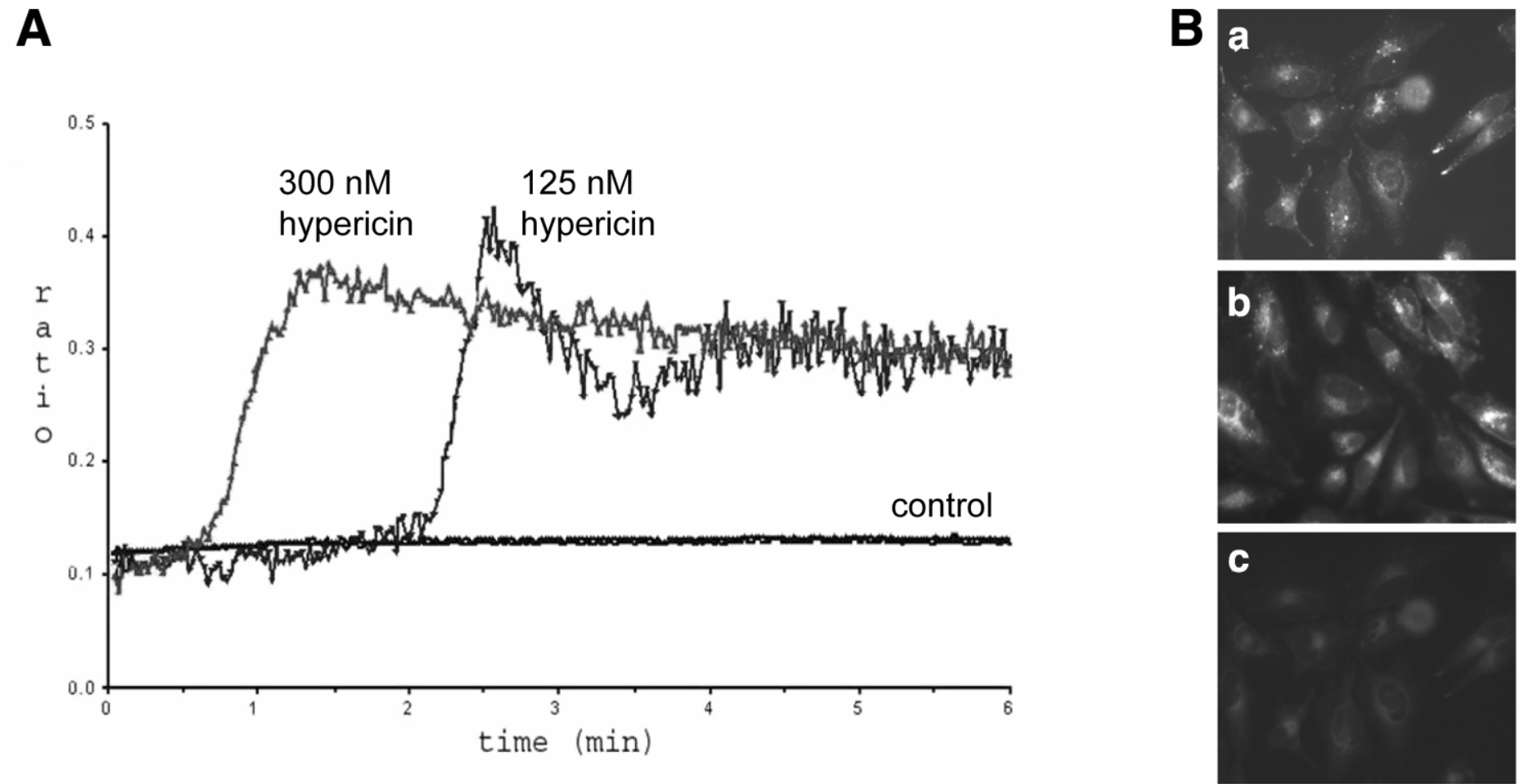

Figure 2. $\left[\mathrm{Ca}^{2+}\right]_{\mathrm{cyt}}$ rise and lysosomal membrane stability after hypericin-PDT. $\boldsymbol{A}$ ) Time course of Indo-1 fluorescence ratio in HeLa cells preincubated with $125 \mathrm{nM}, 300 \mathrm{nM}$ hypericin, or without hypericin (control) for $16 \mathrm{~h}$ before loading with Indo-1-AM, followed by irradiation with UV-light using a confocal laser microscope (MRC-1024UV, Bio-Rad) at time 0. B) HeLa cells were incubated with $125 \mathrm{nM}$ hypericin for $16 \mathrm{~h}$ before irradiation (4 J/cm²). LysoTracker Green DND-26 (75 nM) was added to untreated (a) and PDT-treated $(\boldsymbol{b})$ cells for $1 \mathrm{~h}$ at $1 \mathrm{~h}$ after irradiation before visualization of the cells by fluorescence microscopy. $\boldsymbol{c}$ ) Fluorescence of $125 \mathrm{nM}$ hypericin. 
Fig. 3

A

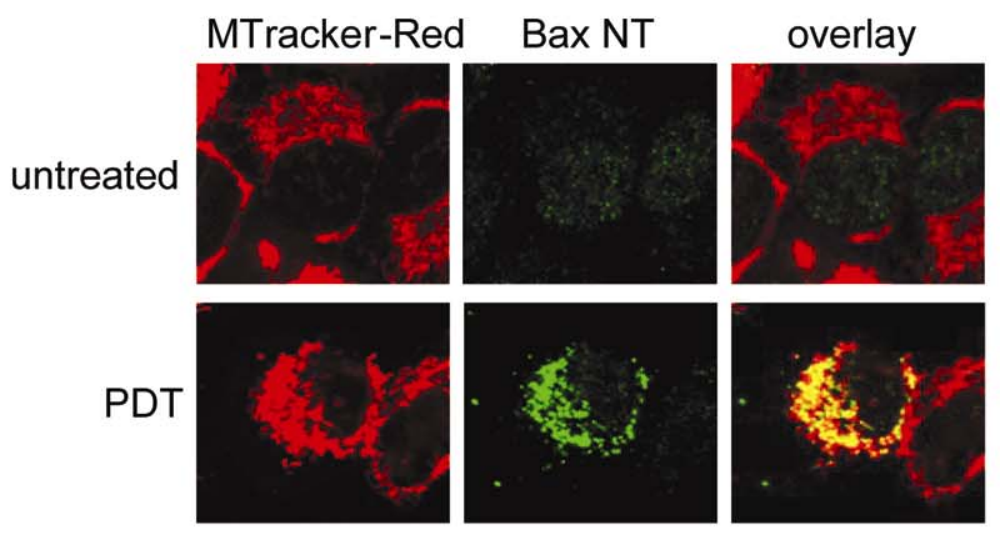

C

B
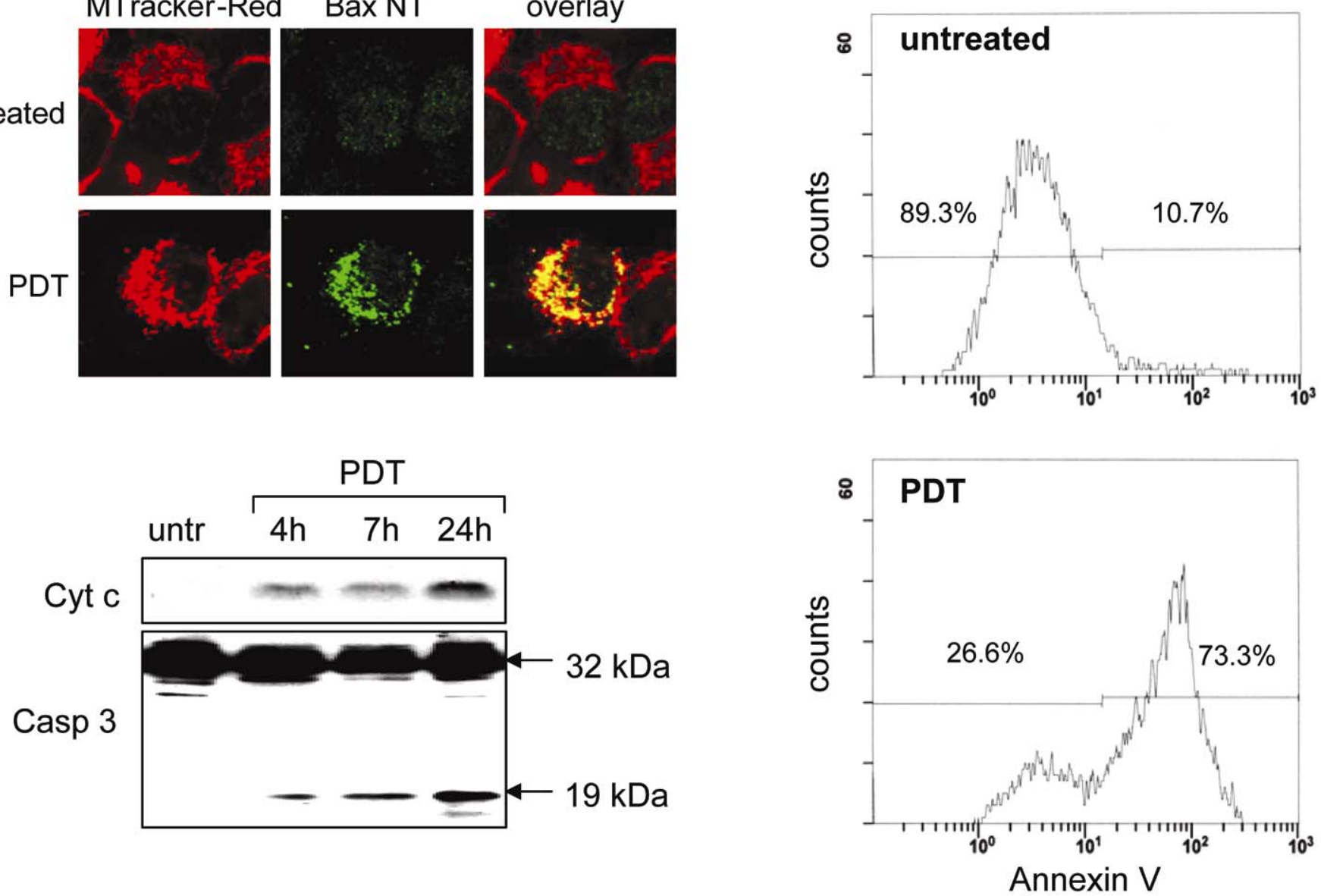

Figure 3. BAX translocation and mitochondrial apoptosis after hypericin-PDT. HeLa cells were incubated with $125 \mathrm{nM}$ hypericin for $16 \mathrm{~h}$ before irradiation $\left(4 \mathrm{~J} / \mathrm{cm}^{2}\right)$. A) Immunocytochemistry of untreated and PDT-treated HeLa cells at $4 \mathrm{~h}$ after irradiation using MitoTracker Red and a conformation specific anti-active BAX antibody (BAX NT) with an Alexa Fluor 488 (green) secondary antibody. Overlay pictures show colocalization of BAX and mitochondria after hypericinPDT by confocal microscopy. B) HeLa cells were harvested at indicated time points after irradiation as described in Materials and Methods and analyzed by Western blot for cytosolic cytochrome $c$ and caspase- 3 using specific anticytochrome $c$ and anti-caspase-3 antibodies (untr=untreated). $\boldsymbol{C}$ ) Flow cytometric analysis of untreated and PDT-treated HeLa cells stained with Annexin V-FITC at $20 \mathrm{~h}$ after irradiation as described in Materials and Methods. Percentages of the indicated regions in the histograms were determined by Expo32 v1.2 software. 
Fig. 4

A

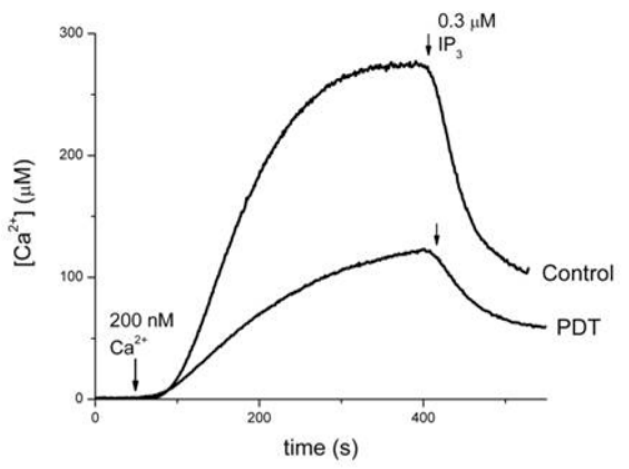

cytAEQ

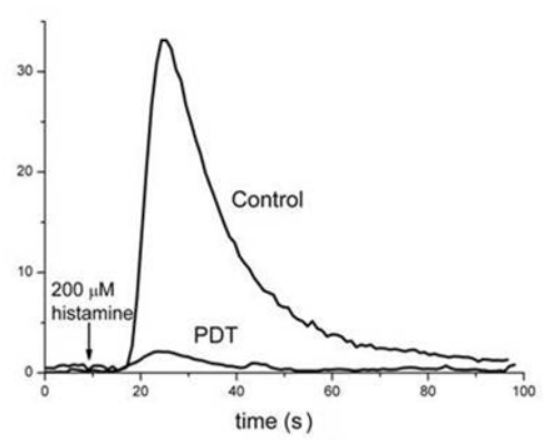

$\mathrm{mtAEQ}$

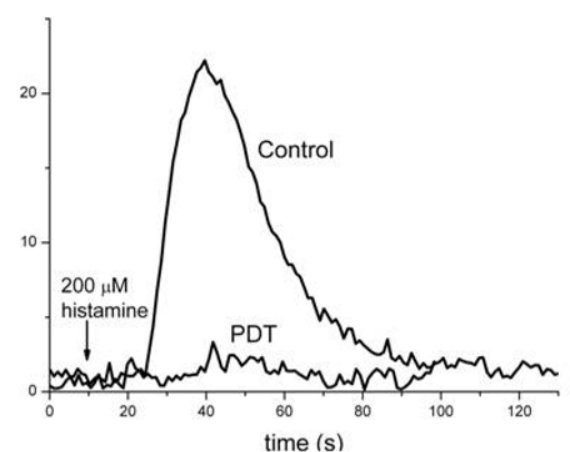

C

B
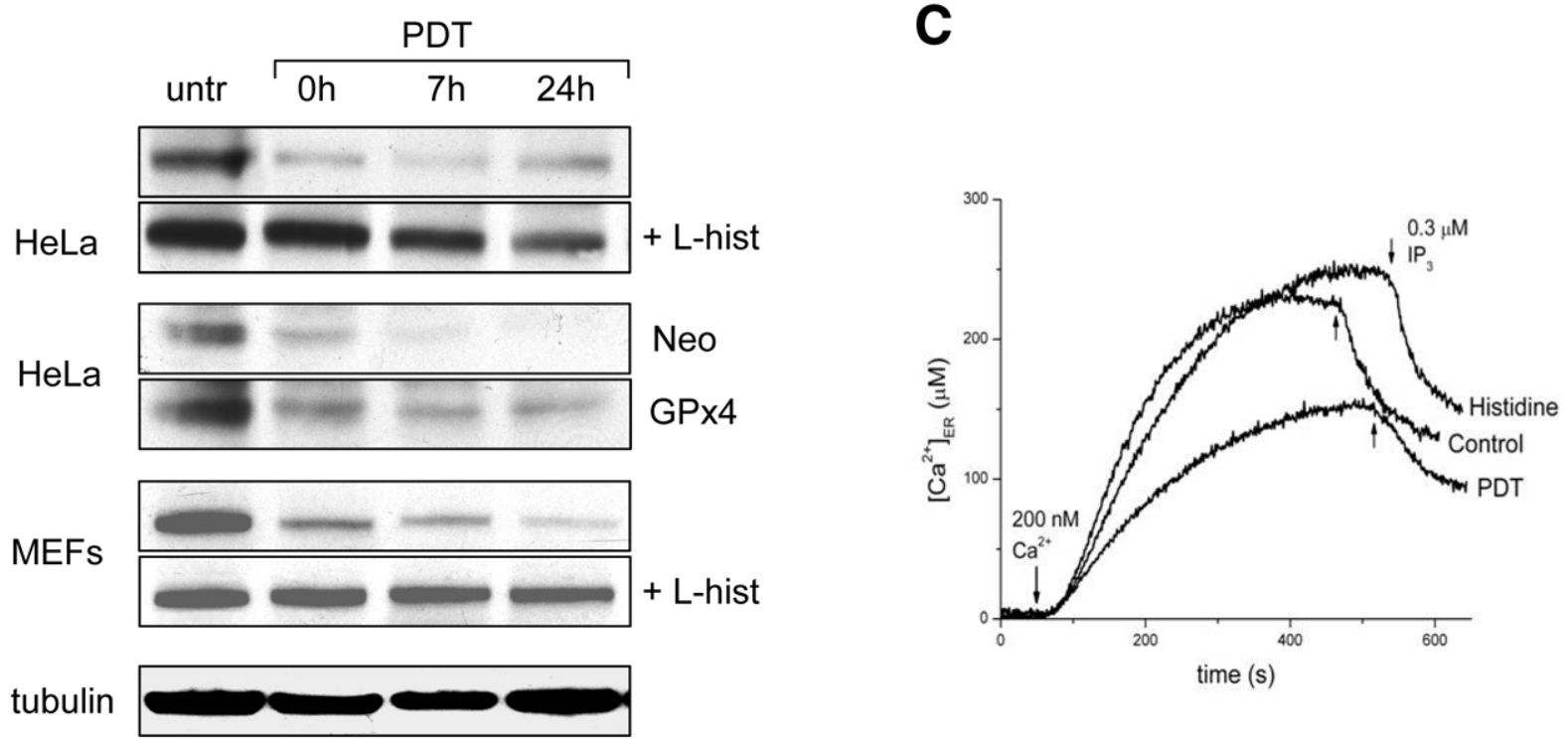

Figure 4. Disturbed $\mathrm{Ca}^{2+}$ homeostasis and SERCA2 photodamage by hypericin-PDT. $\boldsymbol{A}$ ) Representative recording of $\left[\mathrm{Ca}^{2+}\right]$ in ER, cytosol, and mitochondria in HeLa cells transfected with different aequorin constructs (erAEQ, cytAEQ, and mtAEQ, respectively). Cells were transfected for $24 \mathrm{~h}$ before incubation with $125 \mathrm{nM}$ hypericin for $16 \mathrm{~h}$, followed by PDT treatment (control=untreated). erAEQ-transfected HeLa cells were permeabilized with $100 \mu \mathrm{M}$ digitonin before addition of $200 \mathrm{nM}$ free $\mathrm{Ca}^{2+}$ as indicated. ER-Ca ${ }^{2+}$ release was triggered by $0.3 \mu \mathrm{M} \mathrm{InsP}\left(\mathrm{IP}_{3}\right)$, added at the time indicated by the arrow. $\mathrm{Ca}^{2+}$ signals in mtAEQ- and cytAEQ-transfected HeLa cells were measured in modified KRB containing $1 \mathrm{mM} \mathrm{CaCl}_{2}$. The cells were placed in the perfusion chamber at $37^{\circ} \mathrm{C}$, and $200 \mu \mathrm{M}$ histamine was added when indicated. Traces represent the average of 4-8 measurements from a representative experiment. Each experiment was repeated at least twice. $\boldsymbol{B}) \mathrm{HeLa}$ cells, HeLa Neo/GPx4, and MEFs loaded with $125 \mathrm{nM}, 65 \mathrm{nM}$, and $200 \mathrm{nM}$ hypericin, respectively, as described in Materials and Methods, were harvested at the indicated time points $(0 \mathrm{~h}=\mathrm{immediately})$ after irradiation ( $4 \mathrm{~J} / \mathrm{cm}^{2}$ for HeLa cells and $2.7 \mathrm{~J} / \mathrm{cm}^{2}$ for MEFs). Cells were pretreated for $30 \mathrm{~min}$ with $25 \mathrm{mM} \mathrm{L}$-histidine (Lhist) before irradiation where indicated. Cell lysates were analyzed by Western blotting for SERCA2 using a monoclonal antibody that recognizes both SERCA2a and SERCA2b (Clone IID8). Equal protein levels were confirmed with a specific anti-tubulin antibody (a representative blot is shown). $C$ ) Representative recording of $\left[\mathrm{Ca}^{2+}\right]_{\mathrm{ER}}$ in untreated (control) and PDT-treated HeLa cells transfected with erAEQ as described in $\boldsymbol{A} .200 \mathrm{nM} \mathrm{Ca}^{2+}$ and $0.3 \mu \mathrm{M} \mathrm{InsP} \mathrm{P}_{3}\left(\mathrm{IP}_{3}\right)$ were added during the measurement where shown by the arrows. L-histidine $(25 \mathrm{mM})$ was added $30 \mathrm{~min}$ before PDT treatment $\left(4 \mathrm{~J} / \mathrm{cm}^{2}\right)$ where indicated. 
Fig. 5
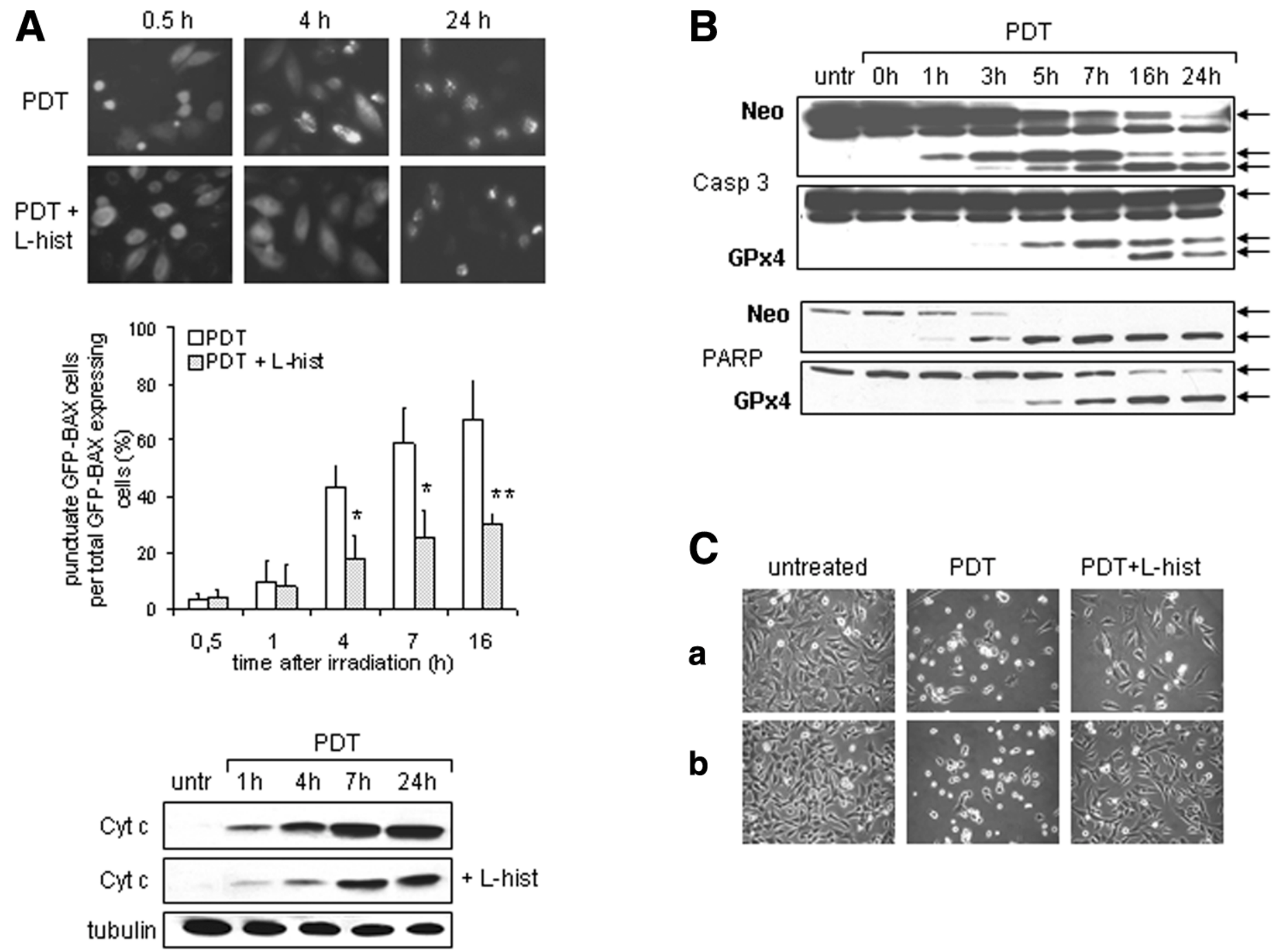

b
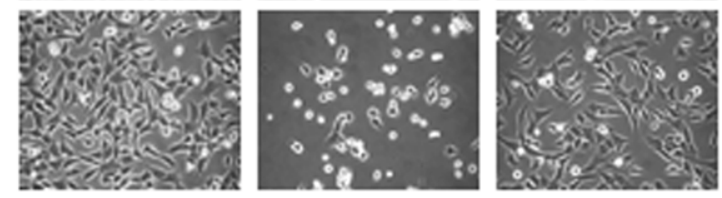

Figure 5. L-histidine and overexpression of GPx4 reduce cell death following hypericin-PDT. A) HeLa cells were transiently transfected with GFP-BAX. After $24 \mathrm{~h}$, the cells were incubated with $125 \mathrm{nM}$ hypericin for $16 \mathrm{~h}$, followed by irradiation $\left(4 \mathrm{~J} / \mathrm{cm}^{2}\right)$. L-histidine (L-hist; $25 \mathrm{mM}$ ) was added $30 \mathrm{~min}$ before irradiation where indicated. Upper panels) Fluorescence micrographs of GFP-BAX-transfected HeLa cells at indicated time points after irradiation and a timedependent increase in cells displaying a punctuate GFP-BAX (green) pattern. At indicated time points, cells with a translocated GFP-BAX pattern were counted by fluorescence microscopy and expressed in percentage per total GFPBAX-transfected cells. Error bars represent SD of three independent experiments. $* P<0.05$ and $* * P<0.01$ represent statistical differences between PDT vs. PDT+L-hist treated cells. Lower panel) Time-dependent increase of cytosolic cytochrome $c$ in HeLa cells after irradiation, analyzed on Western blot using a specific anti-cytochrome $c$ antibody. Equal protein levels of the cytochrome $c$ blot were confirmed with a specific anti-tubulin antibody. B) HeLa Neo and HeLa GPx 4 cells were incubated for $16 \mathrm{~h}$ with $65 \mathrm{nM}$ hypericin, followed by irradiation $\left(4 \mathrm{~J} / \mathrm{cm}^{2}\right)$. Cells were harvested at indicated time points after irradiation and subjected to Western blot analysis using a specific anti-PARP and a specific anti-caspase-3 antibody. $\boldsymbol{C}$ ) WT (a) and DKO-SERCA (b) MEFs were incubated for $2 \mathrm{~h}$ with $200 \mathrm{nM}$ hypericin, followed by irradiation $\left(2.7 \mathrm{~J} / \mathrm{cm}^{2}\right)$. L-histidine $(25 \mathrm{mM})$ was added $30 \mathrm{~min}$ before irradiation where indicated. Light microscopic fields of the cells are shown at $24 \mathrm{~h}$ after irradiation. 
Fig. 6
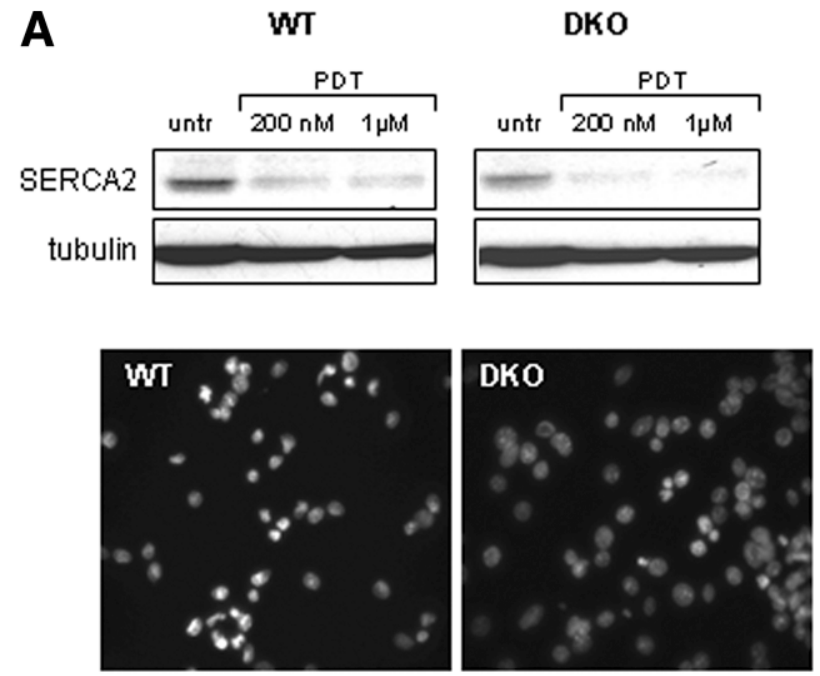

B

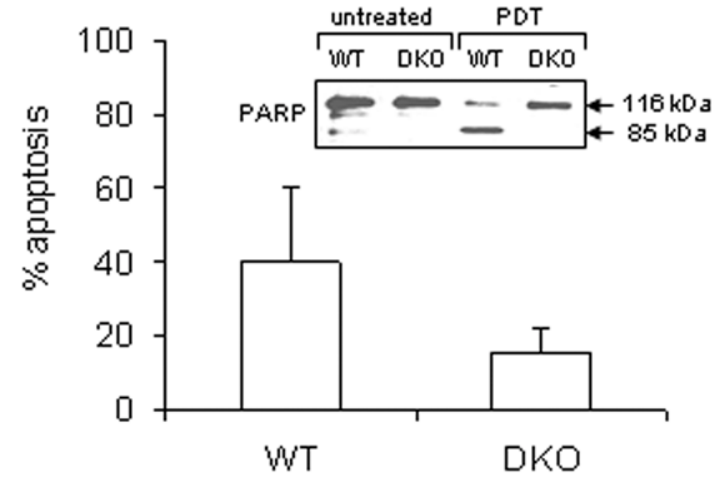

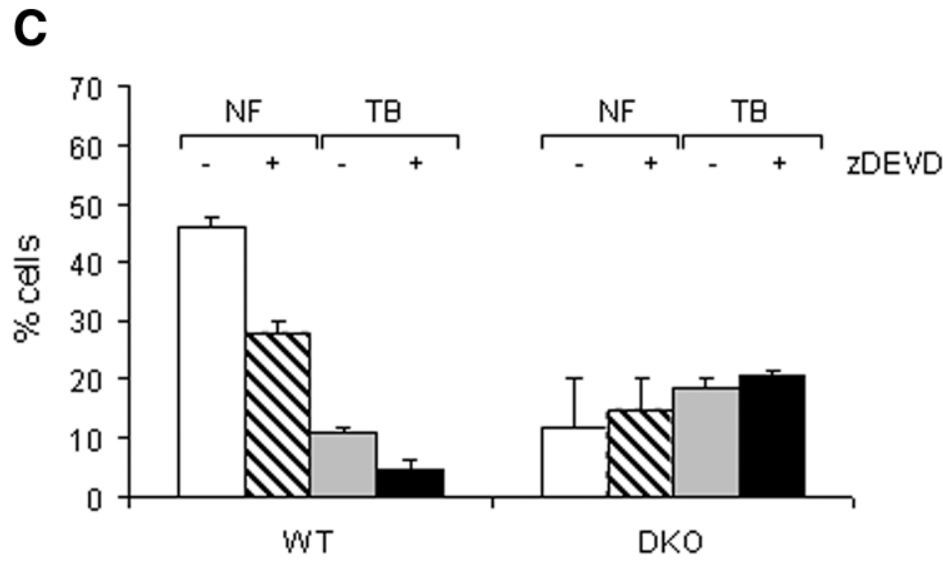

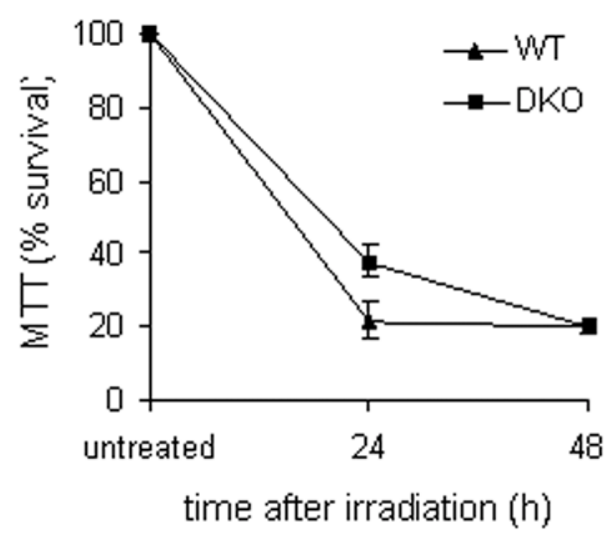

Figure 6. Resistance of MEFs double deficient for BAX and BAK to PDT mediated apoptosis. $A$ ) WT and DKO MEFs were incubated for $2 \mathrm{~h}$ with either $200 \mathrm{nM}$ or $1 \mu \mathrm{M}$ hypericin as indicated, followed by irradiation $\left(2.7 \mathrm{~J} / \mathrm{cm}^{2}\right.$ and 0.5 $\mathrm{J} / \mathrm{cm}^{2}$, respectively). Cells were harvested at $6 \mathrm{~h}$ and $2 \mathrm{~h}$, respectively, after irradiation and analyzed on Western blot for SERCA2 detection with a polyclonal SERCA2b antibody. Equal protein levels were confirmed using a specific antitubulin antibody. B) Apoptotic analysis by nuclear Hoechst 33342 staining of WT vs. DKO MEFs. The cells were incubated with $1 \mu \mathrm{M}$ hypericin for $2 \mathrm{~h}$ before irradiation $\left(0.5 \mathrm{~J} / \mathrm{cm}^{2}\right)$ and then analyzed $1 \mathrm{~h}$ after irradiation using a fluorescence microscope. Similar results were obtained when cells were irradiated with a higher fluence $\left(2.7 \mathrm{~J} / \mathrm{cm}^{2}\right) \mathrm{in}$ combination with a lower concentration of hypericin $(200 \mathrm{nM})$ as shown in $\boldsymbol{C}$. Percentage of cells showing fragmented nuclei was calculated from inspection of at least 10 randomly chosen fields (40-50 cells/field) as represented in the pictures. Values of their corresponding controls (untreated cells, $<5 \%$ ) were substracted from the values of the PDTtreated cells. Error bars represent SD of 2 independent experiments. Lower panel) Inset shows untreated and PDT-treated (1 $\mu \mathrm{M}$ hypericin) WT and DKO MEFs that were harvested $2 \mathrm{~h}$ after irradiation $\left(0.5 \mathrm{~J} / \mathrm{cm}^{2}\right)$ and analyzed on Western blot for PARP cleavage. $C$ ) Nuclear fragmentation (NF) by Hoechst 33342 staining and cell viability by trypan blue uptake (TB) of WT vs. DKO MEFs. Cells were incubated with $200 \mathrm{nM}$ hypericin, and $50 \mu \mathrm{M}$ zDEVD-fmk (where indicated) was added for $2 \mathrm{~h}$ before irradiation $\left(2.7 \mathrm{~J} / \mathrm{cm}^{2}\right)$. Percentage of cells showing fragmented nuclei or trypan blue uptake was calculated as described in $\boldsymbol{B} . \boldsymbol{D})$ Time course of WT and DKO MEFs cell viability after hypericin-PDT. Cells were incubated with $200 \mathrm{nM}$ hypericin for $2 \mathrm{~h}$ before irradiation $\left(2.7 \mathrm{~J} / \mathrm{cm}^{2}\right)$. At indicated time points, cell viability was measured using the MTT assay as described in Materials and Methods. Cell viability of untreated MEFs (control) was normalized to $100 \%$ (day 0 ). 
Fig. 7

A

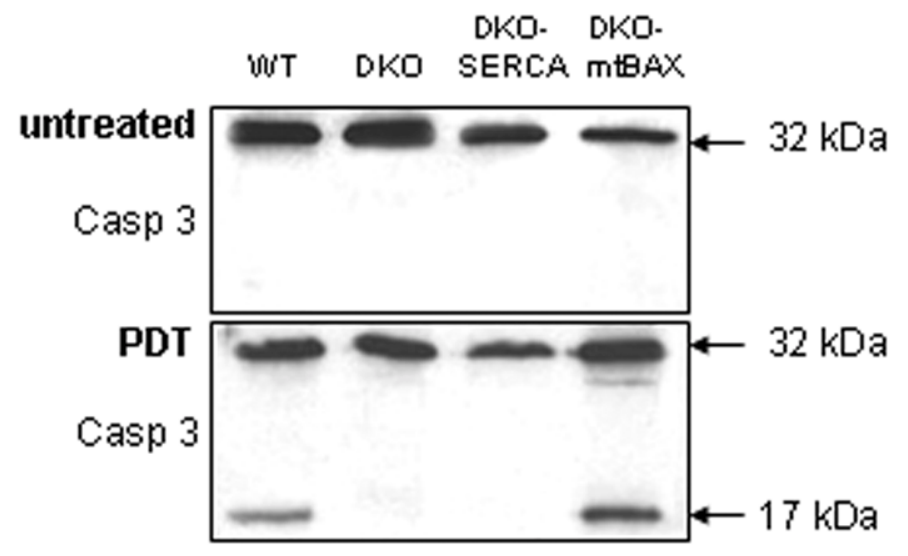

B

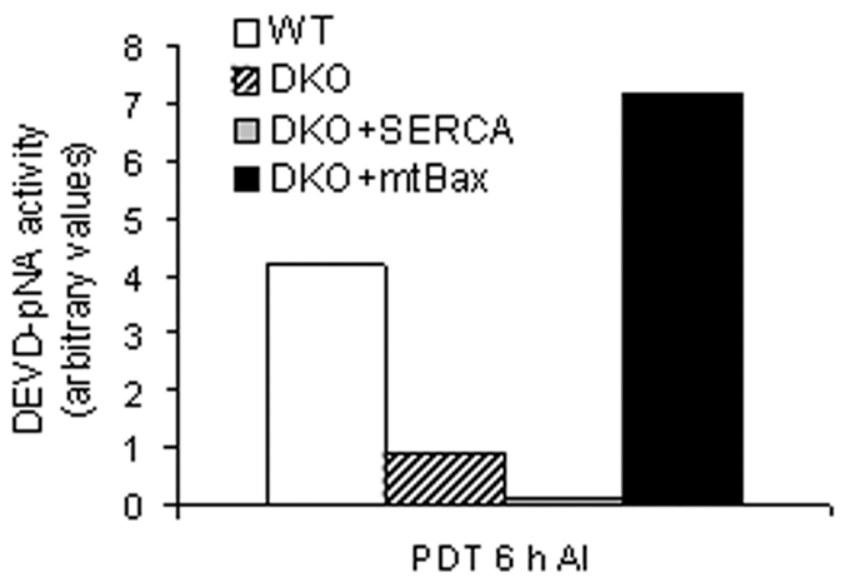

Figure 7. Caspase-3 activation in hypericin-PDT-treated MEFs. MEFs were incubated with $200 \mathrm{nM}$ hypericin for $2 \mathrm{~h}$, followed by irradiation $\left(2.7 \mathrm{~J} / \mathrm{cm}^{2}\right)$. A) WT, DKO, DKO-SERCA, and DKO-mtBAX MEFs were harvested $6 \mathrm{~h}$ after irradiation and analyzed by Western blot for caspase-3 cleavage using a specific anti-caspase-3 antibody. B) Caspase-3 activity in the different MEFs using Ac-DEVD-pNA as the substrate as described in Materials and Methods. Absorbance values, measured at $405 \mathrm{~nm}$, of untreated cells were substracted from the absorbance values of the PDT-treated cells. 
Fig. 8
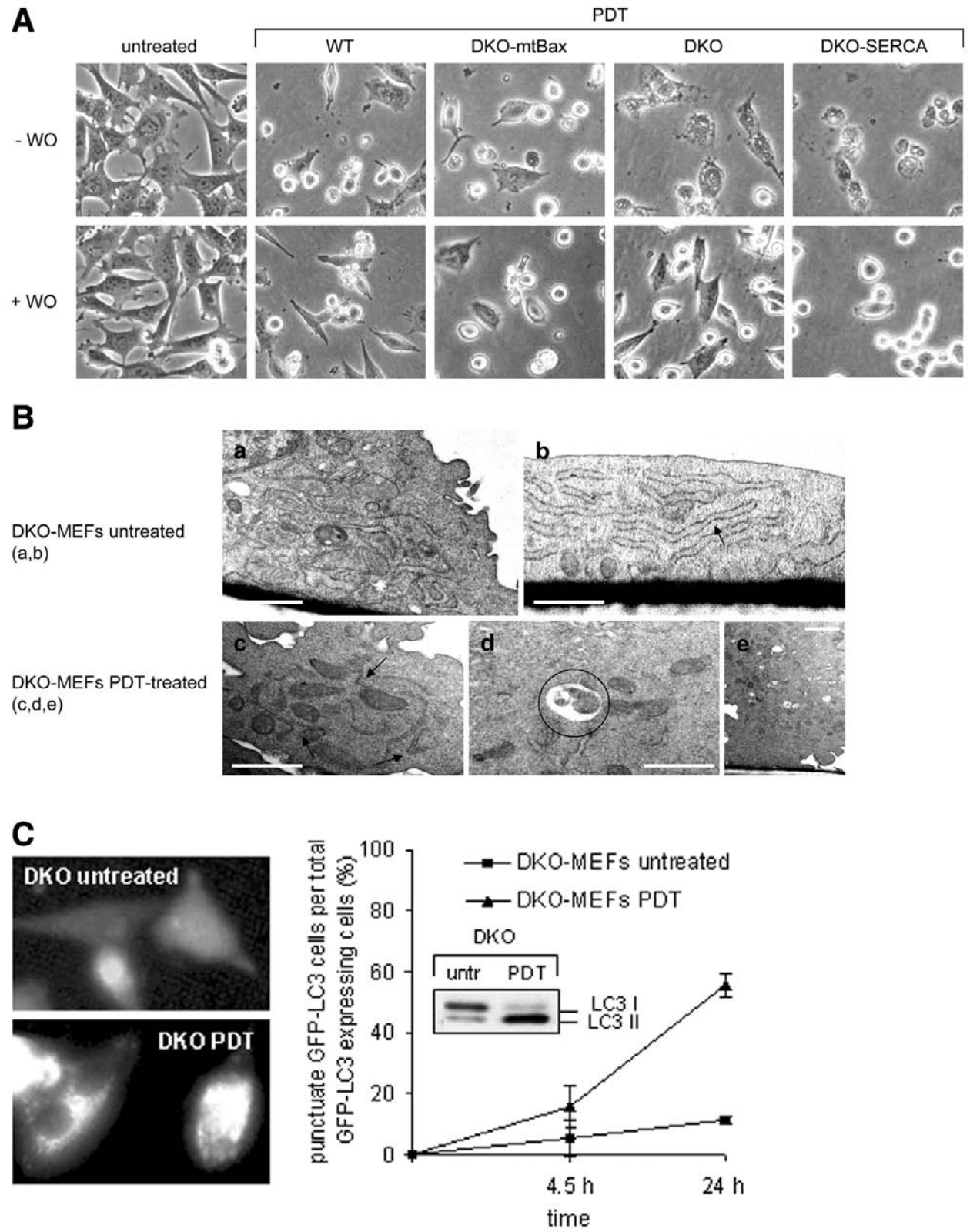

Figure 8. PDT of DKO and DKO-SERCA MEFs induces autophagic cell death. $A$ ) WT, DKO, DKO-mtBAX, and DKOSERCA MEFs were incubated with $1 \mu \mathrm{M}$ hypericin for $2 \mathrm{~h}$, and, where indicated, with $100 \mathrm{nM}$ wortmannin (WO) for $1 \mathrm{~h}$ before irradiation $\left(0.5 \mathrm{~J} / \mathrm{cm}^{2}\right)$. Light microscopic fields are shown for WT, DKO, DKO-mtBAX, and DKO-SERCA MEFs analyzed $2 \mathrm{~h}$ after irradiation. Untreated WT MEFs are shown as representative controls. $B$ ) Transmission electron microscopic analysis showing untreated and PDT-treated DKO MEFs $4 \mathrm{~h}$ after irradiation. Untreated DKO cells $(\boldsymbol{a}, \boldsymbol{b})$ feature a normal morphology with prominent ER profiles (arrows in $\boldsymbol{b}$ ) and a few clear vacuoles. PDT-treated DKO $(\boldsymbol{c}-\boldsymbol{e})$ cells show double-layered membranes engulfing parts of the cytoplasm as well as mitochondria (arrows in $c$ ), autophagic vacuoles containing organelles (a mitochondrion in this case; circle in $\boldsymbol{d}$ ), and highly vacuolated cells $(\boldsymbol{e}$ ). $\boldsymbol{a}-\boldsymbol{d}$ ) Bars $=0.7$ $\mu \mathrm{m} . \boldsymbol{e})$ Bars $=5 \mu \mathrm{m}$. Note that due to the higher cellular density required for the TEM analysis, the intensity of the photodynamic stress $\left(1 \mu \mathrm{M}\right.$ hypericin, $\left.0.5 \mathrm{~J} / \mathrm{cm}^{2}\right)$ was somehow reduced (52) and resulted in a slower progression of autophagy as compared with the PDT-treated cells shown in $\boldsymbol{A}$. $\boldsymbol{C}$ ) DKO MEFs were transiently transfected with GFPLC3. After $18 \mathrm{~h}$, the cells were incubated with $200 \mathrm{nM}$ hypericin for $2 \mathrm{~h}$, followed by irradiation $\left(2.7 \mathrm{~J} / \mathrm{cm}^{2}\right)$. Left panel) Fluorescent micrographs of untreated and PDT-treated DKO MEFs at $24 \mathrm{~h}$ after irradiation. Right panel) Time-dependent increase in cells displaying a punctuate green (GFP-LC3) pattern. Error bars represent SD of 2 independent experiments. Inset shows a Western blot analysis of untreated and PDT-treated (at $6 \mathrm{~h}$ after irradiation) DKO-MEFs for processing of LC3 I into its autophagosome membrane-associated form LC3 II, with a specific anti-LC3 antibody. 
Fig. 9

$\mathbf{A}$

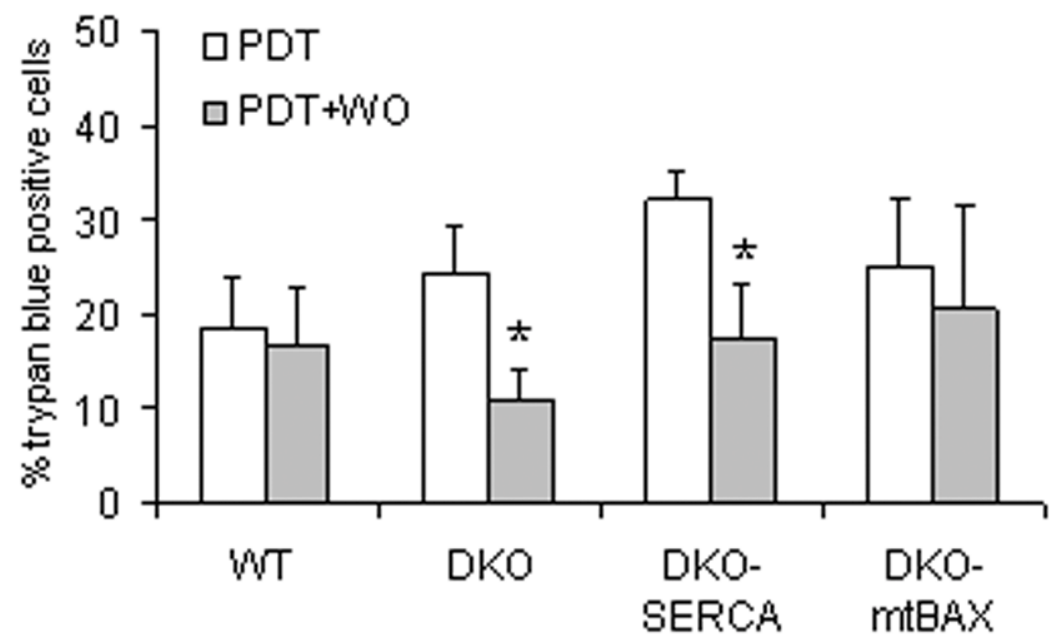

B

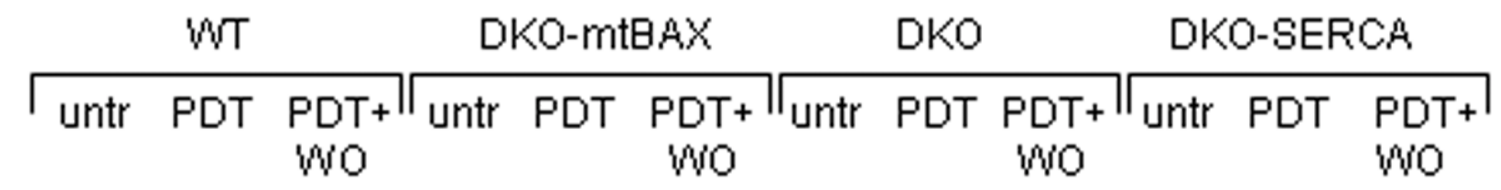

$\mathrm{LC} 3 \mathrm{I}$

LC3 II

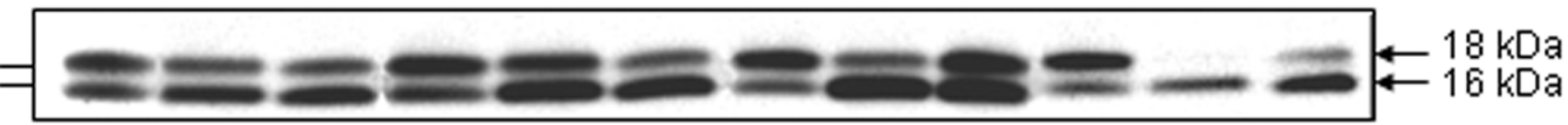

C

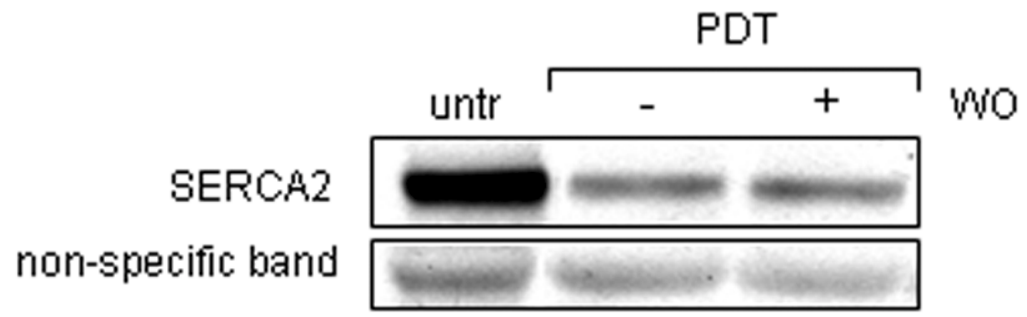

Figure 9. Inhibition of autophagy by wortmannin protects DKO and DKO-SERCA MEFs from photokilling. WT, DKO, DKO-mtBAX, and DKO-SERCA MEFs were incubated with $1 \mu \mathrm{M}$ hypericin for $2 \mathrm{~h}$, and, where indicated, with $100 \mathrm{nM}$ wortmannin (WO) for $1 \mathrm{~h}$ before irradiation $\left(0.5 \mathrm{~J} / \mathrm{cm}^{2}\right)$. A) Cell death measured by trypan blue uptake of WT, DKO, DKO-mtBAX, and DKO-SERCA MEFs at $2 \mathrm{~h}$ after irradiation. Untreated MEFs showed a percentage of trypan bluepositive cells that was $<0.5 \%$. Error bars represent SD of 3 independent experiments. $* P<0.05$ represents statistical differences between PDT-treated cells vs. PDT-treated cells in the presence of WO. B) WT, DKO, DKO-mtBAX, and DKO-SERCA MEFs were harvested $2 \mathrm{~h}$ after hypericin-PDT and analyzed on Western blot for processing of LC3 I into its autophagosome membrane-associated form LC3 II, with a specific anti-LC3 antibody. $C$ ) DKO-SERCA MEFs were harvested at $2 \mathrm{~h}$ after irradiation and subjected to Western blot for detection of SERCA2 using a monoclonal SERCA2a/2b antibody. Equal protein loading is confirmed by a nonspecific band. 
Fig. 10

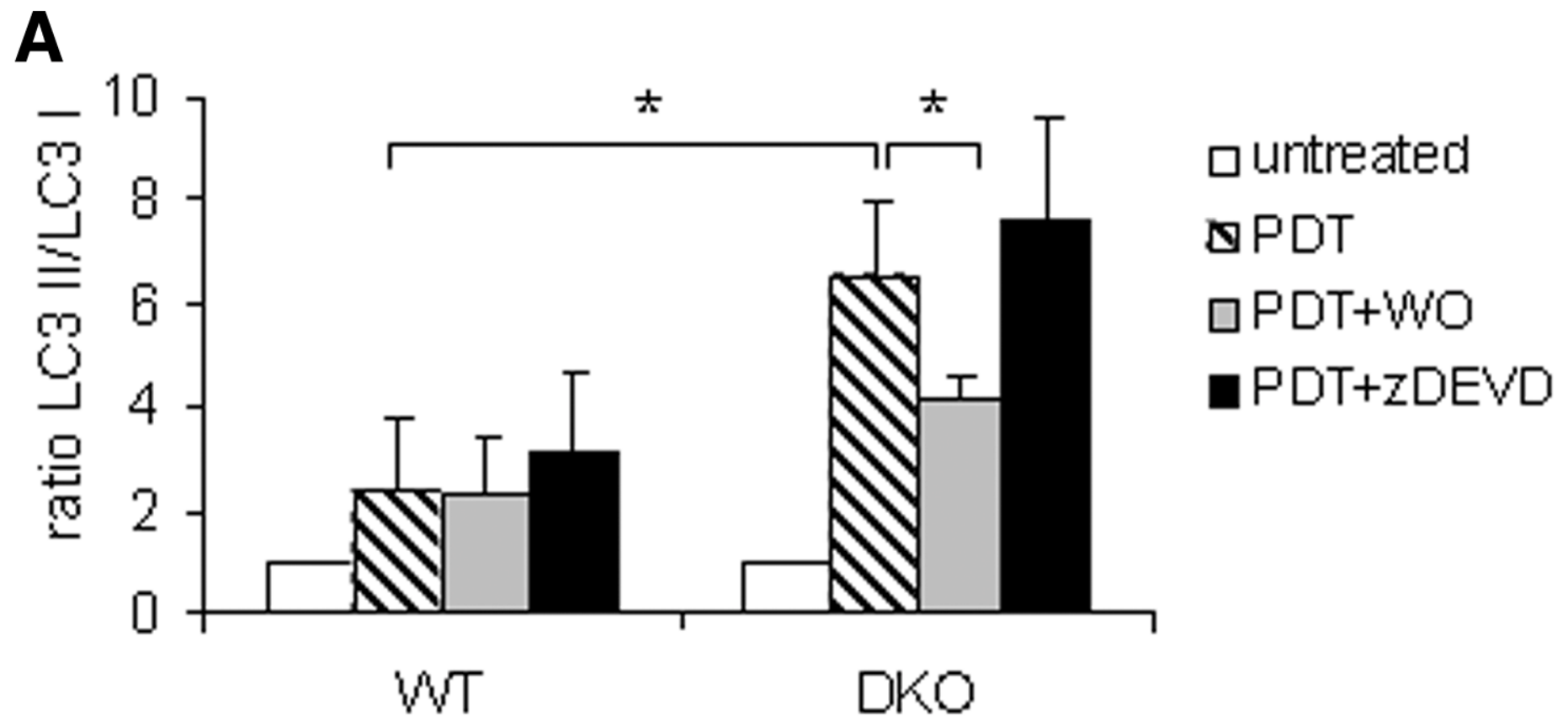

B
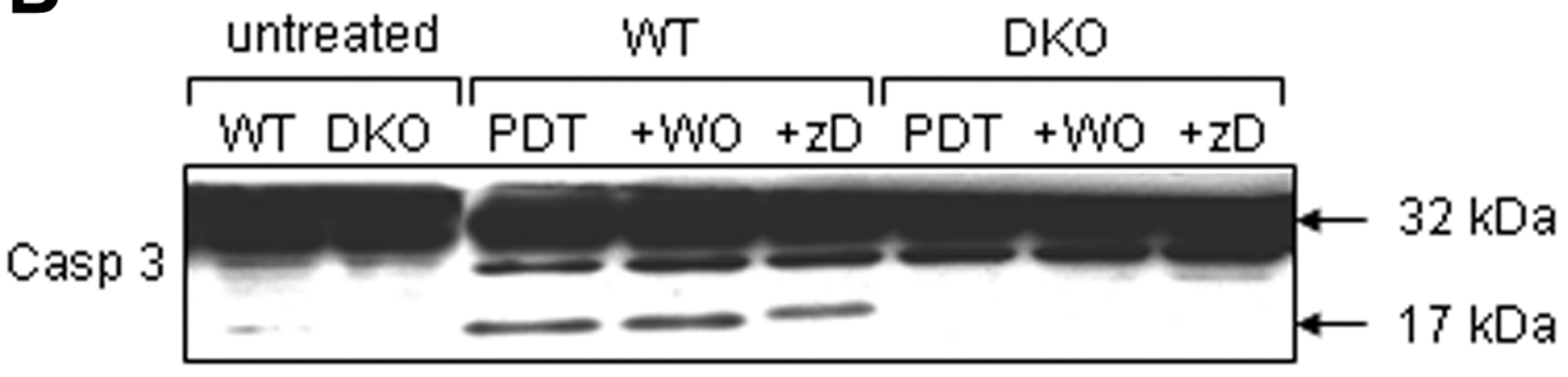

Figure 10. Autophagy after hypericin-PDT is not mediated by caspase activation. WT and DKO MEFs were incubated with $200 \mathrm{nM}$ hypericin for $2 \mathrm{~h}$ before irradiation $\left(2.7 \mathrm{~J} / \mathrm{cm}^{2}\right)$. Where indicated, the cells were incubated with $100 \mathrm{nM}$ wortmannin (WO) or $50 \mu \mathrm{M}$ z-DEVD-fmk (ZD) for 1 and $2 \mathrm{~h}$ before irradiation, respectively. $A$ ) Cells were harvested $6 \mathrm{~h}$ after irradiation. The graph shows ratio LC3 II/LC3 I as quantified from Western blot analysis of LC3 I processing into LC3 II using a specific anti-LC3 antibody with the ImageMaster software (Amersham Biosciences), in which ratio LC3 II/LC3 I in untreated cells was set as 1 . Error bars represent SD of 3 independent experiments. $* P<0.05$ represents statistical differences between groups as indicated. Similar results were observed when cells were photosensitized with 1 $\mu \mathrm{M}$ hypericin. $\boldsymbol{B})$ Lysates used in $\boldsymbol{A}$ were also subjected to Western blot analysis for detection of caspase-3 cleavage using a specific anti-caspase 3 antibody. 
Fig. 11
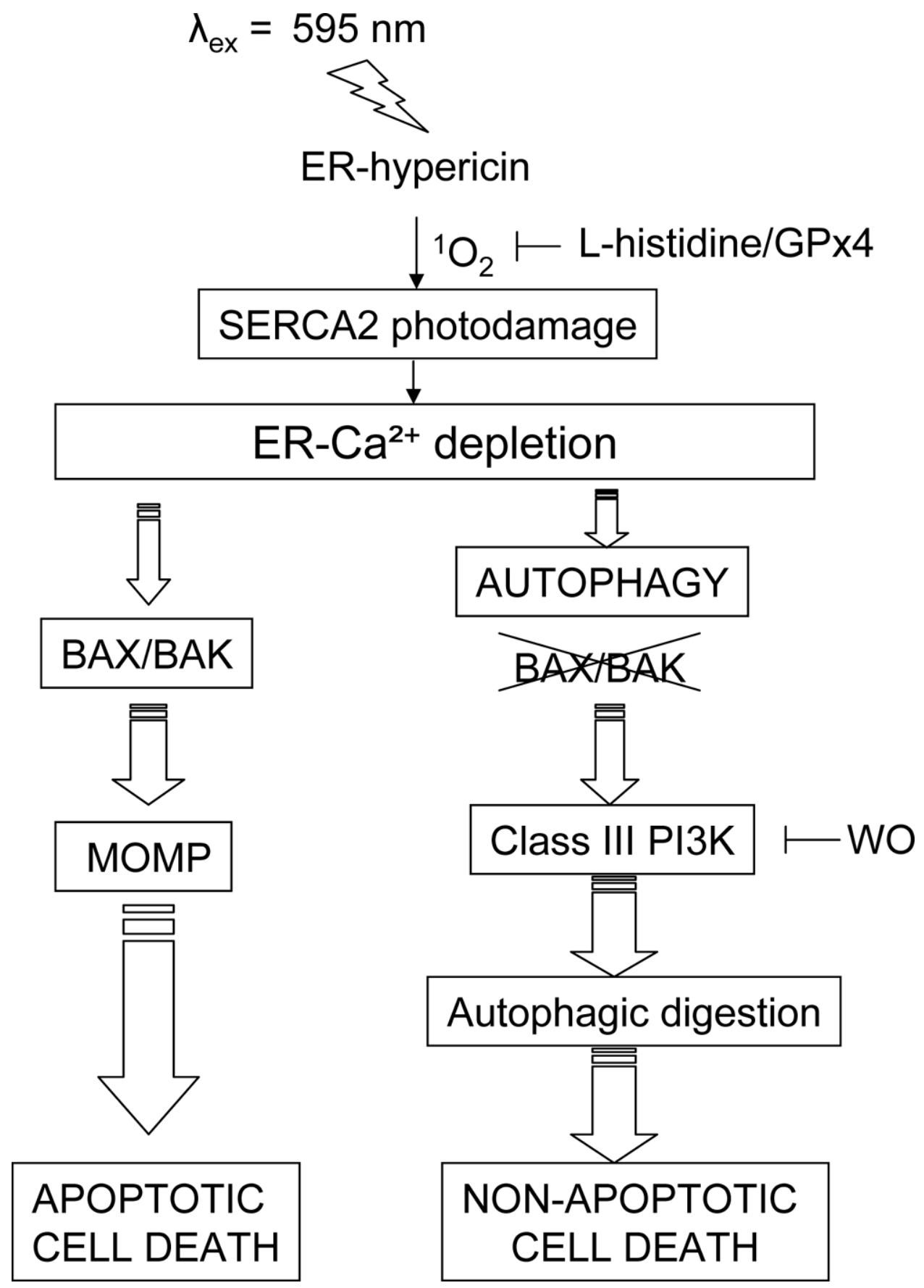

Figure 11. Schematic overview of the main cell death pathways induced by hypericin-PDT. Upon light activation, ERassociated hypericin mediates oxidative damage to the SERCA2 pump through the photogeneration of singlet oxygen $\left({ }^{1} \mathrm{O}_{2}\right)$, causing irreversible depletion of ER-Ca ${ }^{2+}$ stores. Downstream of the ER, the presence of the proapoptotic BAX/BAK proteins promotes mitochondrial outer membrane permeabilization (MOMP), leading to apoptotic cell death. However, PDT-induced emptying of ER-Ca ${ }^{2+}$ stores can activate a wortmannin-inhibitable autophagic pathway, which is revealed by the absence of multidomain BAX/BAK proteins and occurs without detection of MOMP. Sustained progression of the autophagic pathway leads to nonapoptotic death of $\mathrm{Bax}^{-/-} \mathrm{Bak}^{-/-}$DKO cells. 